\title{
Knightian Uncertainty and Interbank Lending
}

\author{
Matthew Pritsker
}




\title{
Knightian Uncertainty and Interbank Lending
}

\author{
Matthew Pritsker*
}

August 16, 2012

\begin{abstract}
The bursting of the housing price bubble during 2007 and 2008 was accompanied by high interbank spreads, and a partial breakdown of interbank lending. This paper theoretically models how Knightian uncertainty over banks risk exposures may have contributed to the breakdown. The paper shows: 1) the two-tier structure of the U.S. Fed Funds market makes it robust to uncertainty, but the market may nevertheless collapse - and private incentives to restart it may be insufficient. 2) In some circumstances government bank audits and information releases about exposures that resemble a stress test can restart markets and improve welfare by internalizing an externality associated with economy-wide uncertainty reduction. 3) Collapses due to uncertainty are less likely ex-ante and less costly to fix ex-post when there is better publicly available information on core banks aggregate risk exposures. Based on 2) and 3), ex-ante and ex-post "transparency initiatives" are proposed. Their success depends on the financial architecture of bank interlinkages.

\section{Keywords: Banking, Risk, Knightian Uncertainty JEL Classification Numbers: G21, G32}

*Federal Reserve Bank of Boston. This is the working paper version of "Knightian Uncertainty and Interbank Lending," which is forthcoming in the Journal of Financial Intermediation. Although many of the results are similar, the published and working paper versions of the paper differ substantially. The views in this paper are those of the author but not necessarily those of the Board of Governors of the Federal Reserve System, the Federal Reserve Bank of Boston, or other members of the Federal Reserve System. This work was begun while the author was visiting NYU Stern School of Business. The author thanks without implicating Thomas Sargent, Anthony Saunders, Viral Acharya, Tanju Yorulmazer, Douglas Gale, Rangarajan Sundaram, Karan Bhanot, Wenying Jiangli, Andrei Kirilenko, Tobias Adrian, Borys Grochulski, and seminar participants at the Federal Reserve Bank of New York, the Federal Reserve Board, the Federal Reserve Bank of Kansas City, the Federal Reserve Bank of Atlanta, and the Bank of Canada for useful conversations and comments. Contact info: The Federal Reserve Bank of Boston, 600 Atlantic Avenue, Boston, MA 02210. Phone: (617) 973-3191. Email:matthew.pritsker@bos.frb.org. 


\section{Introduction}

The U.S. housing price boom of 2000-2006 was accompanied by the proliferation of housing backed collateral in the form of mortgage-debt that was repackaged, and resold to investors and banks, both in the US, and around the world. In the wake of the collapse of housing prices, a global financial crisis ensued in which major institutions failed, financial market volatility rose to historically unprecedented levels, interbank spreads were sharply elevated, interbank credit extension was sharply reduced, and governments needed to take many actions to address the crisis. ${ }^{1}$

An important aspect of the crisis beyond the increase in risk, was severely heightened uncertainty that resulted from the interaction of a riskier economic environment and a buildup of structural economic uncertainty, which means incomplete knowledge of the structure of the economy. In the crisis, structural uncertainty was exemplified by incomplete knowledge of the risk exposures of financial insitutions and instruments to various sources of risk in general, and housing risk in particular. Intuitively, precise knowledge of risk exposures is not important when risk is low, but can become important when risk is elevated, and lead to more cautious behavior that further exacerbates a crisis: when housing prices declined and housing risk became elevated, it was unclear who had taken large losses and who was still exposed; as a result counterparty risk evaluation became problematic, and financiers became unwilling to lend.

This paper models the effects of structural uncertainty over risk exposures on the functioning of interbank markets. The results show that institutional aspects of the interbank market in the U.S. allow it to often function well in the face of structural uncertainty. This allowed structural uncertainty to build-up in good times, while occasionally causing market breakdowns in bad times. When breakdowns occur, because uncertainty reduction is a public good, private incentives to restart the markets may prove to be inadequate, but in some circumstances government provision of information can restart markets and improve welfare by reducing economy-wide uncertainty during a crisis. Two information provision policies are proposed. The first reduces uncertainty by releasing information on systemically important (core banks) risk exposures during a crisis, and is a variant of the bank stress tests that were used by the US in 2007-2009. The second releases information on core banks risk limits and their aggregated across banks risk exposures during normal times. This policy helps bound the financial health of the average core bank, while preserving the privacy of

\footnotetext{
${ }^{1}$ For details on money market spreads in the U.S., Europe, and Japan, see Heider et al. (2009), and Taylor and Williams (2009).
} 
individual banks' exposures. In the context of stylized examples these policies are shown to reduce the welfare costs and likelihood of a breakdown in interbank markets, and reduce the costs of restarting markets if a breakdown should occur.

If structural uncertainty can impede the function of markets, then market institutions should appear that reduce the effects of structural uncertainty. This paper studies interbank market from a structural uncertainty perspective and on that basis shows why the interbank market in the US has a multi-tiered structure in which many large banks trade with each other anonymously in the top tier, while small banks are largely excluded from the top tier as borrowers, but can occasionaly borrow from large banks on a bilateral basis. A key insight from the analysis is when small sectors of the economy are performing poorly, then uncertainty about which banks are exposed to small sectors is relatively unimportant for large banks by virtue of their size. As a result, segments of the interbank market that are dominated by large banks are relatively resilent to uncertainty about exposure to shocks emanating from small sectors of the economy, but not necessarily from large sectors.

Before proceeding further it is useful to clarify the relationship between risk, uncertainty, and structural uncertainty. A decision maker faces risk if the outcomes from his decisions are random. He faces uncertainty if the outcomes are random and he does not know the probabilities of the outcomes. Uncertainty, as used here is also referred to as Knightian uncertainty. An important source of uncertainty is incomplete knowledge of the structure the economic environment, which is referred to above as structural uncertainty.

Experiments such as those of Ellsberg (1961) show that individuals behave more cautiously when confronted with uncertain gambles. This suggests increases in uncertainty about probability distributions can impair market function. A canonical example illustrates how uncertainty arises naturally in banking, how it is tied to risk and structural uncertainty, and why it can be harmful. Consider a loan officer who can make a loan in one of two communities, $A$ or $B$. In both communities there are two types of indistinguishable borrowers $H$ and $L$ that have high- and low- risk default probabilities $p^{H}$ and $p^{L}\left(p^{H}>p^{L}\right)$. In community $A$ the loan officer knows the proportions of $H$ and $L$ types are $\pi^{H}(A)$ and $1-\pi^{H}(A)$. If the loan officer lends in community $A$, the probability that his borrower is an $H$ type is just its proportion in the population, $\pi^{H}(A)$. Community $B$ is just like community $A$, except that the loan officer has limited information on the proportion of $\mathrm{H}$ and L-type borrowers that takes the form $\pi^{H}(B) \in\left[\underline{\pi}^{H}(B), \bar{\pi}^{H}(B)\right]$. This means he has a range for the proportion of high and low risk borrowers, but does not know enough to have beliefs over the proportions that can be described by a probability distribution. The lack of well formed 
beliefs is a source of structural uncertainty in community $B$.

The loan officer's knowledge implies that lending in community $A$ only involves risk since the loan officer knows the probability a loan in $A$ will default is:

$$
P D(A)=\pi^{H}(A) p^{H}+\left[1-\pi^{H}(A)\right] p^{L} .
$$

Conversely, in community $B$, because the loan officer does not know or have a probability distribution for $\pi^{H}(B)$, he does not know $P D(B)$. Nevertheless, using equation 1 , for every possible $\pi^{H}(B) \in\left[\underline{\pi}^{H}(B), \bar{\pi}^{H}(B)\right]$ he can calculate a probability of default. Therefore, he believes there is a range of plausible values for $P D(B)$ given by:

$$
\begin{aligned}
P D(B) & \in\left[\underline{\pi}^{H}(B) p^{H}+\left(1-\underline{\pi}^{H}(B)\right) p^{L}, \bar{\pi}^{H}(B) p^{H}+\left(1-\bar{\pi}^{H}(B)\right) p^{L}\right] \\
& =[\underline{P D}(B), \overline{P D}(B)] .
\end{aligned}
$$

This means, if the loan officer was asked to assess the probability a loan will default in community $B$, he might state he does not know, but believes it could range from 1 to 3 percent. The fact he cites a range is the consequence of his structural uncertainty. Even though he does not know $P D(B)$, if the upper bound of his interval for it is low enough, and the spread he can charge in community $B$ is high enough, he may rationally decide to extend the loan.

If the loan officer sets his spread based on the high end of his range for $P D(B)$, he is choosing it in an uncertainty averse fashion based on his worst case belief, which guarantees his loan spread will cover the highest possible default probability. ${ }^{2}$ This may not be too harmful to borrowers in community $B$ in most circumstances, but can become important. To illustrate, note that the range of uncertainty over default probabilities depends on the

\footnotetext{
${ }^{2}$ Gilboa and Schmeidler (1989) provide an axiomatic foundation for uncertainty averse behavior when agents uncertainty about probabilities is modeled by assuming that agents hold multiple prior distributions over economic state-variables, and then make optimal choices based on on worst-case beliefs about those priors. The loan officer example can be understood as an application of multiple priors in which each prior assigns probability one to a single value of $\pi^{H}(B)$ and 0 to the other values. The other analysis in the paper has a similar interpretation. Empirical evidence that supports modeling behavior towards uncertainty based on worst-case beliefs is provided in Bossaerts et al (2010). For treatments of Knightian Uncertainty in a smooth setting that places weight on worst case and other priors see Klibanoff et al (2005); for treatments in a dynamic setting see Hansen and Sargent (2008), Chen and Epstein (2002), and Epstein and Schneider (2003). An excellent recent survey of the literature that is oriented towards asset pricing is Guidolin and Rinaldi (2010).
} 
interaction of structural uncertainty and risk:

$$
\begin{aligned}
& {[\overline{P D}(B)-\underline{P D}(B)]=\left[\bar{\pi}^{H}(B)-\underline{\pi}^{H}(B)\right] \times\left(p^{H}-p^{L}\right)} \\
& =\text { Structural Uncertainty } \times \text { Risk }
\end{aligned}
$$

During good times, if all borrowers are unlikely to default, then $p^{H}$ and $p^{L}$ are likely to be small and close to each other. In such circumstances, even if there is structural uncertainty, the uncertainty over default probabilities will be small and not matter much. Conversely, in bad times $p^{H}$ may be much greater than $p^{L}$; and in this circumstance uncertainty over the proportion of high and low risk borrowers leads to a wide range of potential default probabilities. If lenders set their spreads in an uncertainty averse fashion, it can then lead to very large spreads that choke some borrowers out of the market.

The same problems that uncertainty and uncertainty averse behavior can cause for borrowers in community $B$ can also occur in the interbank market because in analogy with uncertainty over the proportion of high risk borrowers, a creditor bank may have incomplete knowledge about a borrowing bank's portfolio weights, and hence that bank's default probability. This uncertainty may matter when times are bad, and in some circumstances can impair the function of interbank markets.

The paper is related to literature on Knightian uncertainty, the financial crises of 2007-09, and on the structure of interbank markets. ${ }^{3}$ The most closely related literature on Knightian Uncertainty examines how it has or should shape government and market institutions. Easley and O'Hara (2009 and 2010) interpret policies that trim rare tail events in banking and financial markets as being motivated by uncertainty reduction, the most prominent such policy being deposit insurance. In the presence of Knightian Uncertainty over liquidity availability, Caballero and Krishnamurthy (2008) show that government liquidity assistance can be highly effective because the knowledge it will be forthcoming reduce worst-case beliefs over liquidity needs and leads to complementary liquidity provision from private sources. This paper adds to this literature by linking Knightian to structural uncertainty, and show that government policies and market institutions that reduce structural uncertainty also help to address Knightian uncertainty.

The most closely related papers on the crisis are by Gary Gorton and coauthors [Gorton (2008), Gorton (2009), Metrick and Gorton (2009), and Dang, Gorton, and Holmstrom

\footnotetext{
${ }^{3}$ The paper is also related to the literature on corporate transparency and asset pricing. Duffie and Lando (2001) theoretically show and Yu (2005) empirically literature confirms that imprecise accounting figures can affect firms borrowing costs, especially for short-rated debt.
} 
(2009)]. Their main argument is when housing prices declined, the value of AAA securitization tranches became highly sensitive to the portfolio composition of the assets backing the tranches. The sensitivity created incentives for market participants to gather information on the assets, and the ensuing asymmetric information caused repo spreads and haircuts to severely widen, and repo borrowing to effectively collapse.

Both this paper and the Gorton papers emphasize increased sensitivity of debt values to asset composition as a cause of the crisis, but are otherwise complementary for three reasons. First, this paper studies collapse through heightened uncertainty, while theirs studies collapse due to asymmetric information. Second, the papers differ in economic setting, and implications for policy. In an endowment economy, Dang, Gorton, and Holmstrom (2009) show that symmetric ignorance about the value of endowments is better than symmetric information, and therefore more bank transparency is not desirable. This paper instead considers a production economy where production can only occur if there is enough information about banks to allow financial intermediation. Consequently, better information about banks is sometimes needed and this improves welfare. Third, the Gorton papers focus on secured (repo) borrowing, while this paper focus on unsecured interbank borrowing. ${ }^{4}$

There is a small related literature on the structure of interbank markets. Allen and Saunders [1986] present a theoretical model in which small banks are excluded from interbank markets because of adverse selection. Consistent with the adverse selection interpretation Allen et al (1989) find that small banks are limited in their participation as unsecured but not secured borrowers in interbank markets. ${ }^{5}$ Ashcraft et al (2009) also find that small banks are constrained in their ability to borrow in interbank markets. This paper questions the pure adverse selection interpretation of small banks exclusion because large banks are often much more opaque and complicated than small banks, but are nevertheless very frequent borrowers in unsecured interbank markets. Instead, this paper presents a framework in which large and small banks are equally opaque, but because of Knightian uncertainty small banks are excluded as borrowers from the top tier of the interbank market. An additional contribution of this paper is that it models the multi-tier structure of the interbank market.

The remainder of the paper contains 4 sections. The next section presents our model

\footnotetext{
${ }^{4}$ In complementary research [Heiderer et. al (2009) uses adverse selection to model the collapse of interbank markets during the crisis of 2007-2009; in addition alternative policy interventions to address the collapse are evaluated.

${ }^{5}$ Ho and Saunders (1985) present a model in which small banks do more lending than borrowing in interbank markets because they face a greater risk of not meeting their reserve requirements. This explanation is inconsistent with the fact that small banks are active on both sides of secured interbank borrowing markets as in Allen et al (1989).
} 
of the economy and studies interbank loan spreads and market breakdown in the bilateral lending tier of the interbank market. Section 3 presents our model of lending in the top tier of the market, and when both tiers are operating together, and uses it to analyze steps the government can take to fix markets that breakdown, and institutional features of the Federal Funds market that help to prevent breakdown. Section 4 discusses how network interlinkages affect government efforts to prevent breakdown. A final section concludes.

\section{Model}

Our basic framework is of a stylized competitive economy that has $M$ economic sectors, and $2 N$ large banks that make loans to those sectors for the purposes of long term investments and for short-term liquidity needs. There are three dates, 0,1 , and 2 . At date 0 the banks raise funds from depositors and equity holders and invest those funds in long-term loans that mature at date 2. At date 1, macroeconomic news arrives. In addition each bank experiences either a funding shock that provides it with more deposits, or a lending shock that provides it with opportunities to make short-term loans, but not both. Following the news and shocks, banks use the interbank market to channel funds from those banks that have excess funds to those banks that have excess lending opportunities. The heart of the paper analyzes the institutions in the Federal Funds market that facilitate this transfer of funds at date 1 in the presence of uncertainty. To close the model, at date 2 , the returns on banks loan portfolios are realized, and banks pay back their stakeholders if fully solvent-or default and make partial payments if not solvent.

\section{$2.1 \quad$ Date 0}

At date 0 , each large bank $i=1, \ldots 2 N$ is endowed with a fixed amount of equity $E_{i}$, and then chooses to raise insured deposits $D_{i}$ to fund a long-term asset portfolio of size $A_{i}$ $\left(A_{i}=D_{i}+E_{i}\right)$. Including deposit insurance premium payments, for each dollar of deposits the bank pays interest $R^{D}$ that is fixed and does not depend on the banks portfolio weights. ${ }^{6}$

The long-term asset portfolio consists of investments in $M$ sector-portfolios that each consist of infinitesimal loans to borrowers in the $M$ sectors of the economy. Bank $i$ 's portfolio

\footnotetext{
${ }^{6}$ This is with little loss of generality since banks as modeled here face other regulatory constraints which keep their premium small.
} 
weight is denoted by the $M$-vector $\omega_{i}$. The return between dates 0 and 2 on the sector portfolios is denoted by the $M$-vector $R$, whose distribution is provided below and derived in the appendix:

Proposition 1 Under regularity conditions given in the appendix, $R$, the gross return received at date 2 per dollar invested at date 0 , is distributed multivariate normal conditional on $I_{0}$ and $I_{1}$, the information available at date 0 and date 1 :

$$
\begin{aligned}
R \mid I_{0} & \sim \mathcal{N}[\mu, \Sigma] ; \\
R \mid I_{1} & \sim \mathcal{N}[\mu(1), \Sigma(1)] ; \\
\text { where } \mu & =\alpha ; \\
\mu(1) & =\alpha+\beta f(1) .
\end{aligned}
$$

Proof: See the appendix.

In the proposition, $f(1)$ is a $K \times 1$ vector of factors which represents news about the macro-economy that is learned at date 1 ; and $\beta$ is an $M \times K$ matrix of factor sensitivities which indicates how different sectors load on the factors. The proof of the proposition relates the return parameters to the structure of the macro-economy and lending markets. For the purposes of the paper, these properties are taken as given to focus the analysis on the interbank market.

Given bank $i$ 's equity endowment $E_{i}$, it chooses it portfolio weights and insured deposits $\left(\omega_{i}\right.$ and $\left.D_{i}\right)$ to maximize $V_{i}(0)$ the present value of the cashflows that the long-term loans produce for its shareholders after the banks depositors are repaid. The banks shareholders are modeled as risk-neutral and uncertainty averse, and thus the value of its long-term loan portfolio is given by the expression: ${ }^{7}$

$$
\begin{aligned}
V_{i}(0) & =\max _{\omega_{i}} E\left\{\frac{\max \left[\left(E_{i}+D_{i}\right) \omega_{i}^{\prime} R-D_{i} R^{D}, 0\right]}{\left(1+R^{f}\right)^{2}}\right\} \\
& ==\max _{\omega_{i}} E\left\{E_{i} \frac{\max \left[R^{D}+\left(1+L_{i}\right)\left(\omega_{i}^{\prime} R-R^{D}\right), 0\right]}{\left(1+R^{f}\right)^{2}}\right\}
\end{aligned}
$$

where $L_{i}$ is bank $i$ 's leverage ratio given by $L_{i}=D_{i} / E_{i}$, and $R^{f}$ is the net risk-free rate. Note that in this optimization at date 0 the bank ignores the possibility that it may not be able to fund the short-term lending opportunities that arise at date 1, and therefore fails to

\footnotetext{
${ }^{7}$ Each banks shareholders are modeled as insiders who know the banks' own portfolio holdings, but not that of other banks.
} 
hedge against this possibility. This is rational because the lending and funding shocks are exactly offsetting within the banking sector. Therefore, the loans at date 1 will be funded provided that the interbank market functions well, which is very likely. ${ }^{8}$

The optimation in 4 is conducted subject to two regulatory constraints. The first places an upper bound on its leverage:

$$
L_{i} \leq \bar{L}
$$

The second places an upper bound on its probability of default conditional on date 0 information $P D_{i}\left(\omega_{i}, 0\right)$, and thus resembles a constraint on the firms credit value at risk:

$$
P D_{i}\left(\omega_{i}, 0\right) \leq \bar{K}
$$

The bank will default and become insolvent at date 2, if the returns on its loan portfolio are insufficient to cover its deposits. Under the reasonable assumption that its long-term loan portfolio is much bigger than its short-term portfolio, its short-term portfolio can be ignored for determining insolvency. Then, a little bit of algebra shows the probability of default is:

$$
P D_{i}\left(\omega_{i}, 0\right)=\Phi\left(\frac{\frac{L_{i}}{1+L_{i}} R^{D}-\omega_{i}^{\prime} \mu}{\sqrt{\omega_{i}^{\prime} \Sigma \omega_{i}}}\right),
$$

where $\Phi($.$) is the Standard Normal CDF.$

If the bank only faced regulatory constraints, algebra shows that for whatever leverage choice $L_{i}$ is optimal, the bank's optimal asset portfolio would have the maximal mean return and maximal standard deviation that satisfies the credit value at risk constraint. ${ }^{9}$ Using mean-variance portfolio theory, this implies that bank $i$ 's optimal portfolio with only regulatory constraints is the risky asset mean-variance efficient frontier, and is such that the value at risk constraint binds. For fixed leverage, the set of portfolios for which the credit value at risk constraint binds is an upward sloping line in mean-standard deviation space, and the regulatory constraint-only optimal portfolio $\bar{\omega}$ is where this line intersects the efficient frontier as illustrated in Figure 1.

In addition to the regulatory constraints, I assume each bank faces internal constraints in choosing its portfolio that could arise from limited underwriting capabilities, constraints

\footnotetext{
${ }^{8}$ Failure to hedge can be interpreted more generally as incomplete hedging. An additional reason for not hedging is that it is very costly because hedging involve giving up long-term lending opportunities in exchange for short-term opportunities that are likely to be less lucrative.

${ }^{9}$ Without the constraints, the banks optimal portfolio would use infinite leverage.
} 
on investment opportunities, or other reasons. Because banks are opaque, I assume the internal constraints faced by each bank are not fully understood by other banks. As a result of the internal constraints, and bank opacity, each bank is uncertain about the other banks portfolio.

Each banks structural uncertainty about other banks banks internal constraints is modeled by assuming banks know the structure of the economy (equation 3), the general maximization problem that banks solve (equation 4) subject to regulatory constraints, and from balance sheets know each bank $i$ 's leverage and total asset holdings. On this basis each bank believes other banks hold a portfolio that satisfies the regulatory constraints and is in a neighborhood near (but because of internal constraints not necessarily equal to ) the regulatory-constrained optimal portfolio $\bar{\omega}$. For modeling convenience, the neighborhood is modeled as a set of portfolios that lie on an interval between $\underline{\omega}$ and $\bar{\omega}$ on the mean variance frontier (Figure 1) . The size of the interval is a reflection of bank $i$ 's opaqueness. Other banks do not know more about bank $i$ 's portfolio than it lies in this interval. ${ }^{10}$ Because mean-variance efficient portfolios are convex combinations of each other (provided there are no restrictions on the size of long or short positions), other banks structural uncertainty about $i$ can be expressed as:

$$
\omega_{i} \in \mathcal{C}(\underline{\omega}, \bar{\omega})
$$

where, $\mathcal{C}(\underline{\omega}, \bar{\omega})$ is the set of portfolios that are convex combinations of $\underline{\omega}$ and $\bar{\omega} .^{11}$

\section{$2.2 \quad$ Date 1}

At date 1 macroeconomic news $f(1)$ arrives, and banks receive lending or funding shocks that for simplicity all have the same magnitude, normalized to 1 . Banks that receive lending and funding shocks are indexed by $i$ and $j$. Each lending shock is a demand to borrow 1 unit until date 2 from a short-term borrower with a reservation interest rate of $\bar{R}_{l}$. Each funding shock is the receipt of an additional unit of funds that can be invested at the risk-free rate until date 2 or loaned out in the interbank market. To simplify the analysis, I make the following assumptions:

\footnotetext{
${ }^{10}$ There are other ways to motivate structural uncertainty and bounds on $i$ 's portfolio weights. The main results in the paper only require that other banks believe $i$ 's portfolios is in a closed, bounded, convex set.

${ }^{11}$ Mathematically,

$$
\mathcal{C}(\underline{\omega}, \bar{\omega})=\{\omega: \omega=\theta \underline{\omega}+(1-\theta) \bar{\omega}, \quad \theta \in[0,1]\} .
$$
}


Assumption 1 Each short-term borrower will default unless screened by it's bank $i$, but will be risk-free if screened.

Assumption 2 Each bank $i$ has monopoly power and charges $\bar{R}_{l}$ for its short-term loans.

These assumptions create a basis for trade between banks $i$ and $j$ because $i$ is short of funds and only $i$ can intermediate loans to its short-term borrower. The tier of the interbank market in which banks $i$ and $j$ trade together is assumed to be competitive. Therefore $R_{i, j}$ the rate on a short-term interbank loan between any bank $i$ and $j$ must be as good as lending at the riskfree rate:

$$
R_{i, j}-R^{f}=\widehat{P D}_{i} L G D_{i}
$$

where $\widehat{P D}_{i}$ is the perceived probability that bank $i$ will default at date 2 given information that is available at date 1 , and $L G D_{i}$ is the loss $j$ experiences if $i$ defaults. I assume throughout that $L G D_{i}$ is known.

Bank $i$ will borrow in the interbank market provided that his borrowing cost is low enough that he can make profitable short-term loans with the funds. This requires that $\bar{R}_{l} \geq R_{i, j}$, which from equation (9) implies the spread $i$ can charge on the short-term loan must be greater than the spread he pays in the interbank market:

$$
\bar{R}_{l}-R^{f} \geq \widehat{P D}_{i} L G D_{i}
$$

The size of the spread $i$ pays depends on how beliefs about $\widehat{P D}_{i}$, are formed, which in turn depends on the trading institutions within the interbank market. There are two main ways in which trade takes place in the market. The first is bilateral in which one bank directly arranges a loan with another; the second is when loans are arranged in an anonymous brokered market. The institutions are treated below and in section 3 .

\subsection{Pricing in the Bilateral Tier w/Uncertainty}

This section models the bilateral exchange tier of the interbank market in which there is a bank $i$ that needs a loan from bank $j$, and borrows directly from bank $j$ when bank $j$ is 
uncertain about bank $i$ 's exposures. ${ }^{12}$ Like the loan officer in the canonical example, bank $j$ is risk neutral, but uncertainty averse. Because of $j$ 's structural uncertainty over $\omega_{i}$, he charges a spread based on his worst case beliefs abouts $P D_{i}$ in the bilateral market $(B M)$, given by:

$$
\widehat{P D}_{i}(B M)=\max _{\omega_{i} \in \mathcal{C}(\underline{\omega}, \bar{\omega})} \Phi\left(\frac{\frac{L_{i}}{1+L_{i}} R^{D}-\omega_{i}^{\prime} \mu(1)}{\sqrt{\omega_{i}^{\prime} \Sigma(1) \omega_{i}}}\right) \equiv P_{H} .
$$

This is also denoted as $P_{H}$; and will play a role in later sections. If we let $\omega_{i}^{*}$ denote $i$ 's true portfolio holdings, and $P D_{i}\left(\omega_{i}^{*}\right)$ be $i$ 's true probability of default, then the spread that $i$ faces can decomposed into a premium for default and an additional premium for uncertainty:

$$
\begin{aligned}
R_{i, j}-R^{f} & =\widehat{P D}_{i}(B M) L G D_{i} \\
& =\left[P D_{i}\left(\omega_{i}^{*}\right) L G D_{i}\right]+\left[\widehat{P D}_{i}(B M)-P D_{i}\left(\omega_{i}^{*}\right)\right] L G D_{i} \\
& =\text { Default Premium + Uncertainty Premium. }
\end{aligned}
$$

Equation 12 is useful for understanding lending during the precrisis period. Prior to the 2007-09 financial crisis the largest banks grew substantially in size, which arguably makes them more opaque, raising the question of why they did not pay higher uncertainty premia for their opaqueness. Because uncertainty premia are proportional to $L G D_{i}$, spreads for uncertainty can be driven down substantially through collateralized borrowing on terms that (i.e. collateral haircuts) make $L G D_{i}$ small. This suggests the enormous growth of repo-borrowing pre-crisis may have helped to avoid uncertainty premia. As noted in the introduction during the crisis uncertainty premia for collateralized borrowing rose because of uncertainty about the value of the collateral.

To investigate how uncertainty spreads remained low in unsecured interbank markets pre-crisis, note that in some conditions, such as those outlined in Case 1, the news that arrives at date 1 unambiguously shrinks the uncertainty premium:

Case 1: $\forall \omega_{i} \in \mathcal{C}\left(\underline{\omega}_{i}, \bar{\omega}_{i}\right)$

(a) $\omega_{i}>0$

\footnotetext{
${ }^{12}$ Later sections of the paper examine signalling to reduce uncertainty in the bilateral market.
} 
(b) $\frac{L_{i}}{1+L_{i}} R^{D}-\omega_{i}^{\prime} \mu<0$

(c) $f(1)$ is such that $\beta_{m} f(1)>0$ for all $m$.

(d) $\Sigma[1]=\rho \Sigma$ for some $\rho \in(0,1)$

The conditions for premia to shrink essentially require lower volatility, and require that the expected return on assets that bank $j$ believes bank $i$ holds in positive amounts increases. These low volatility, positive news conditions are of the sort that prevailed pre-crisis.

Conversely as in case 2 , if bank $j$ believes bank $i$ could have a positive or negative exposure to some sector (such as sector 1 in case 2), then if the news about the expected return in that sector is bad enough, i.e. bounded sufficiently far below 0 , it will increase the uncertainty premium for bank $i$.

Case 2: (a) $\omega_{i}[1] \in[-A, A]$ for some $A>0$.

(b) $\beta_{1} f(1)<\psi<0$.

If $i$ 's potential exposure to sector 1 is large enough, its uncertainty premium may become too high too allow it to finance the short-term loan, causing interbank borrowing between $i$ and $j$ to break down. This generates a welfare loss because the best use of funds is to channel them to bank $i$ 's borrowers.

These results are summarized in the following proposition.

Proposition 2 Although there is structural uncertainty about banki's positions, under some economic conditions (such as case 1), favorable economic news can reduce the loan spread that bank $i$ pays for borrowing in the interbank market. Under other economic conditions, such as those in case 2, sufficiently unfavorable news about some sectors of the economy can destroy bank i's ability to finance its new lending opportunities in the interbank market, effectively causing the interbank market to break down.

Proof: See the appendix.

The proposition shows that the uncertainty spread can be low in the right economic conditions. As shown in Figure 2, reproduced from Pritsker (2010), provided volatility is low enough or the expected return on its loans are high enough (not shown), $i$ 's uncertainty 
premium can remain small even when its leverage is high. However, if leverage is high, and volatility increases, uncertainty premia can increase very sharply. These results explain how uncertainty premia remained small even as leverage grew in the low-volatility and perceived high return environment that prevailed before the 2007-2009 crisis; and they illustrate why uncertainty premia jumped so sharply during the crisis. ${ }^{13}$

The same factors that explain uncertainty premia in the bilateral market also drive premia in the anonymous brokered market, but the magnitude of the uncertainty premium in the anonymous brokered market is different because it depends on how worst case beliefs are formed over the set of possible banks with whom a bank may transact. We turn to this topic in the next section.

\section{Multiple Banks and the Interbank Market for Fed- eral Funds}

This section studies the multi-tier structure of the Federal Funds interbank market, or Fed Funds Market for short, and analyzes its resilience to uncertainty. The analysis contains 5 subsections. Section 3.1 provides an overview of the salient features of the market. The basic model of the upper tier is modeled in section 3.2; steps to restart trade in the upper tier through government information provision are analyzed in section 3.3. Section 3.4 outlines a framework for jointly modeling both tiers and shows that the two-tier structure helps make the market resilient to uncertainty. Public provision of information in normal time can further reduce the effects of uncertainty. This is the subject of section 3.5.

\subsection{The Interbank Market}

This section describes the features of the Fed Funds market that are salient for our analysis. Formally, the interbank market is a market for overnight or longer-term lending in which banks trade with each other to fulfill liquidity needs, meet central bank reserve requirements, and finance new lending. Three facts about the market are important for our analysis:

\footnotetext{
${ }^{13}$ Although the version of the model presented here does not allow volatility to increase at date 1 , it is useful to study the effects of volatility increases at date 1 and the model can be easily generalized to allow for volatility increases by modeling long run asset returns as of date 1 as gaussian under different volatility regimes, and as a normal mixture as of date 0 . All results continue to hold.
} 
1. Many loans are based on repeated relationships in which banks that have a tendency to borrow or lend to each other on a repeated basis face lower rates given other observable variables that are correlated with their credit risk [Furfine, (2001) for the U.S., Cocco et. al. (2009) for the interbank market in Portugal].

2. Many loans take place through an anonymous brokered market in which the borrowers identity is disclosed to a lender only after a match is established at an agreed upon rate:

"While borrowers and lenders may arrange trades directly with one another, larger more sophisticated market participants tend to arrange most of their trades through brokers. A key feature of brokered trading is that trades are initiated anonymously between interested parties, as a borrowers identity is disclosed to a lender only after a match is established at an agreed-upon loan rate. After a match is established and the lender accepts to lend to the borrower (a decision usually conditioned on the presence of a predetermined credit line between the two parties), the trade is deemed 'executed' by the broker." [Bartolini et. al. (2008)]

3. The market has a multi-tiered structure in which small banks are net lenders to medium sized banks; medium-sized banks in turn are net lenders on average to large banks; while large banks primarily extend loans to each other [Allen et. al. (1989), Furfine (1999), and Bech and Atalay (2008)]. ${ }^{14}$ Small banks are largely excluded as borrowers from the top tier of the market.

Relationship-based lending, and borrowing and lending in an anonynmous brokered market are nearly the antithesis of each other. Both exist because the Federal Funds market has a multi-tier structure in which some banks do very significant amounts of trading in the top-tier, which consists of an anonymous brokered market, while other banks engage in relationship lending. In the sections that follow, the paper provides a theory for why the Federal Funds market has a multi-tiered structure, why small banks are excluded from borrowing in the top tier, and why some banks engage in relationship borrowing.

\footnotetext{
${ }^{14}$ Bech and Atalay provide detailed information on the network structure of the market, and the flow of funds through the market. Among other facts in their paper they note that the banks in the center of the market had $\$ 400$ billion dollars of assets on their balance sheets at the end of 2006 .
} 


\subsection{The Anonymous Brokered Market}

This section models the interaction of the multiple large banks that trade in the anonymous brokered market (ABM) that lies at the center or core of the Federal Funds market. Banks that borrow in the ABM are referred to as core banks. ${ }^{15}$ For simplicity, at date 1 each large banks portfolio is modeled as appearing identical to outsiders, which means that all large banks publicly report the same balance sheet leverage and assets; and each banks portfolios are believed to be in $\mathcal{C}[\underline{\omega}, \bar{\omega}] .{ }^{16}$ At the beginning of date 1 , all banks learn the value of $f(1)$. The remaining events at date 1 occur over $M$ sub-periods. In each subperiod, $N$ banks receive lending shocks and $N$ banks receive funding shocks. The shocks have the same form as in section 2.2. ${ }^{17}$ Following the shocks the banks trade to make interbank loans in the anonymous brokered market, and then the next subperiod begins.

Trade in the ABM is modeled as a random matching game among large banks. Bank that need funds each place a bid for a unit amount, and banks that have funds are randomly matched with the bidding banks. If the lending bank consents to the transaction at the agreed upon rate, then a trade is consummated. Otherwise, the borrower and lender do not get the opportunity to again trade in the subperiod. The game gives all of the bargaining power to the borrowing banks. Each borrowing bank captures maximal surplus by proposing to borrow at the lowest possible spread that could be acceptable to lending banks. Since $L G D_{i}$ is identical across banks, and all banks are risk neutral but uncertainty averse, the spread is equal to $\widehat{P D}(A B M) L G D_{i}$, where $\widehat{P D}(A B M)$ is the borrowing bank's assessment of lending banks worst case probability that the loan they make will default. Since all borrowing banks will propose the same estimate of $\widehat{P D}(A B M)$, randomly matching borrowing and lending banks is an equilibrium in the brokered market. ${ }^{18}$

To solve for worst case beliefs, each lending bank accounts for the fact it has a probability $1 /(2 N-1)$ of being randomly matched with any of $2 N-1$ other banks, and that $\omega_{i} \in[\underline{\omega}, \bar{\omega}]$ for each bank. For now it is also assumed that lending banks know the size of the aggregate supply of loans that were made by all core banks in each sector of the economy, denoted

\footnotetext{
${ }^{15}$ It is not clear precisely how much trading large banks in the top tier of the market conduct through brokers. Bartolini et. al. (2008) claim that the largest and most sophisticated participants in the market trade through brokers, while based on conversations with experts Ashcraft and Duffie (2007) suggest that less than $27 \%$ of trades by large banks is conducted this way.

${ }^{16}$ Allowing these to differ would complicate the analysis but have little effect on the main results.

${ }^{17}$ To simplify the analysis all investments made in any subperiod of date 1 mature at date 2 . Additionally, to avoid modelling dynamic hoarding behavior, banks that receive funding shocks in one subperiod cannot hoard the funds until another subperiod.

${ }^{18}$ If signalling is possible, then some banks may choose not to participate in the anonymous brokered market. This topic is discussed extensively in later subsections.
} 
by $Y_{M}$, but do not know precisely how these loans are divided among the banks. The knowledge of $Y_{M}$ imposes a constraint that banks portfolio holdings must add up to the aggregate (equation 14). With this information, the worst case $P D$ that borrowing banks propose is the solution to: ${ }^{19}$

$$
\widehat{P D}(A B M)=\max _{\omega_{k}, k=1, \ldots 2 N} \frac{1}{2 N-1} \sum_{k \neq j}^{2 N} P D_{k}\left(\omega_{k}\right)
$$

such that,

$$
\sum_{k=1}^{2 N} \omega_{k} A_{k}=Y_{M}
$$

and for each bank $k, k=1, \ldots 2 N$,

$$
\omega_{k} \in \mathcal{C}(\underline{\omega}, \bar{\omega})
$$

In concrete terms, the probability that a lender's borrower will default is just the sum of the probability that each borrower will be selected $1 /(2 N-1)$ times the probability that it will default if selected, $P D($.$) . The worst case beliefs simply assign portfolio holdings to$ maximize this probability subject to constraints. To solve for worst case beliefs I make one more mild auxilary assumption which guarantees that the objective function in equation 13 is convex. ${ }^{20}$

Assumption 3 For each bank $k=1, \ldots 2 N$, for every feasible $\omega_{k}, P D_{k}\left(\omega_{k}\right)<0.5$

The worst-case PD is found by noting that the constraint sets and the objective function are both convex. Therefore, the solution lies on the extremes. This means if $P D(\bar{\omega})>P D(\underline{\omega})$ then the solution for worst case beliefs involves believing subject to the constraints as large a percentage (denoted $\theta$ ) of potential borrowing banks as possible hold portfolio $\bar{\omega}$, while the rest (percentage $1-\theta$ ) hold portfolio $\underline{\omega}{ }^{21}$

\footnotetext{
${ }^{19}$ Note: In the maximization borrowing banks compute the worst case beliefs that lending banks could possibly have by also accounting for lending banks portfolios; i.e. worst case beliefs involve assigning lending banks safe portfolios because that worsen beliefs about borrower's portfolios.

${ }^{20}$ The assumption is mild except for severe banking crises.

${ }^{21}$ When equation 14 holds as an equality, then the worst case beliefs involve at most one bank holding a portfolio in the interior of $\mathcal{C}(\underline{\omega}, \bar{\omega}))$ since if more than one did, by convexity $\widehat{P D}_{i}$ could be increased by moving one portfolio up toward $\bar{\omega}$ and the other toward $\underline{\omega}$, which violates the condition that the original
} 
A comparison of $\widehat{P D}(A B M)$ and $\widehat{P D}(B M)$ shows how the two markets handle uncertainty about asset holdings slightly differently. Worst case $P D$ beliefs in the anonymous brokered market are equal to $\theta P^{H}+(1-\theta) P^{L}$ where $P^{H}$ is the default probability associated with the highest default probability portfolio (say $\bar{\omega}$ ), and $P^{L}$ is the default probability associated with other boundary of banks constraint sets $(\underline{\omega})$. Recall that $P^{H}\left[=\widehat{P D}_{i}(B M)\right]$ is the worst-case probability of default in the bilateral market when there is uncertainty. An immediate implication is that worst case PD in the anonymous brokered market are lower than those in the bilateral market with uncertainty. Formally,

Proposition 3 Under assumption 3, and the constraints on beliefs from equations (14) and (15), when there is uncertainty, the spreads that banks pay in the anonymous brokered tier of the interbank market are less than or equal to the spreads they would pay when borrowing in the bilateral tier of the interbank market.

Proof: See the appendix.

The proposition shows that trading with a single bank in the bilateral market when there is uncertainty generates higher spreads than when dealing with a randomly matched bank in the anonymous brokered market. The intuition is that any single bank could hold the worst case portfolio, but it may be impossible for all of them to do so because it may violate the adding-up constraint (equation 14). Therefore, if brokers act to ensure random matching in the anonymous brokered market, then worst case beliefs must account for the randomness of the matching, which then leads to lower spreads than in the bilateral market. ${ }^{22}$

An implicit assumption in the above reasoning is that if a bank is approached to lend in the bilateral market, then the arrival of the borrowing bank is not treated like a random arrival by an uncertainty averse lender. This can be rationalized by noting that banks may not have well formed beliefs about arrivals to borrow outside of the brokered market, and thus treat unanticipated arrivals in the bilateral market suspiciously and charge a higher spread in response. This treatment is analogous to how non-random arrivals are often treated in other

beliefs maximized $P D$. The presence or absence of the "interior-bank" does not alter the results, but for simplicity I pretend it is absent.

${ }^{22}$ This result can also be understood in terms of Schmeidler (1989)'s definition of ambiguity (aka uncertainty) aversion. In particular, Schmeidler defines ambiguity averse preferences as a preference relation that if it is indifferent between two ambiguous lotteries, weakly prefers a mixture of the lotteries to either lottery individually. The reason that the mixture is preferred is that each ambiguous lottery partially hedges the other, which reduces the worst case beliefs about the combined lottery. Mixing among ambiguous banks produces the same result since the worst case beliefs about the mixture are less bad than the worst case beliefs about any bank. 
real world situations. For example, when asking for directions in a crowded train station, it may be fine to ask for help from almost any randomly chosen person, but if a person approaches to offer directions, then that help should be treated more skeptically because of uncertainty over the persons motive in having arrived to offer directions. ${ }^{23}$

The results in proposition 3 are most applicable when lending banks are uncertain about borrowing banks that appear to be outwardly similar. These conditions are more likely to be satisfied for large banks because it should be costly for them to signal, and absent signalling beliefs on portfolios are more likely to depend on a similar set of investment opportunity sets. Therefore, the results in proposition 3 explain why large banks tend to trade with each other in the anonymous brokered market, but do not explain the lending and borrowing patterns of small banks. Those patterns will be explained in section 3.4; and will be based on the examples used in the following section.

\subsection{Market Breakdown and Government Information Provision to Restart Markets}

Although the ABM market structure is more resilient to uncertainty than the bilateral market, it too can breakdown. This section studies how breakdowns occur and why private efforts to restart the ABM may fail while government efforts to restart it may succeed and improve welfare. The ideas for why private efforts may fail and government efforts may succeed are general, but to illustrate them, the analysis is specialized so that there are only two sectors. Loans to a pool of borrowers in sectors 1 and 2 will be referred to as assets 1 and 2. Core banks hold $Y_{M}[1]$ of asset 1 , and each bank $i$ has the capacity to hold the entire stock of that asset $\left(\overline{\omega_{i}} A_{i}[1]>Y_{M}[1]\right)$.

If the news that arrives at date 1 is sufficiently bad for asset 1, then because of convexity, and our assumptions on capacity, the worst-case beliefs that maximize $\widehat{P D}(A B M)$ will involve one borrower bank holding all of asset 1 (and potentially some of asset 2), and the other $2 N-1$ banks holding no exposure to asset 1 . This is equivalent to having the belief that there are $2 N-1$ banks with a low probability of default, $P_{L}$ and one bank with a high probability of default $P_{H}$, which implies: ${ }^{24}$

\footnotetext{
${ }^{23}$ The train station analogy is based on a comment by Pete Kyle.

${ }^{24}$ Recall our convexity assumption requires $P_{H}<0.5$.
} 


$$
\widehat{P D}(A B M)=P_{L}+\frac{1}{2 N-1}\left(P_{H}-P_{L}\right) .
$$

From equation 10, we know that if the worst-case beliefs $\widehat{P D}(A B M)$ exceeds some maximal level, denoted $\overline{P D}$, that financing costs for short-term loans will be too high to justify extending these loans, and hence the interbank market may break down. Assume that the news $f(1)$ is sufficiently bad that it does break down.

One possible solution would be for good banks to signal their quality by revealing information about their portfolios. For simplicity, assume the information fully and credibly reveals the bank's portfolio. In addition, assume the bank can borrow at a rate commensurate with its true credit quality after signalling. If the cost of signaling in this way is $c$, given by

$$
c=\left(\bar{R}_{l}-R^{D}-P_{L} L G D_{i}\right) \times \frac{M}{2}+\epsilon,
$$

for some $\epsilon>0$, where $M$ is the number of subperiods of trade in the ABM, the signalling cost is equal to the expected surplus a good bank could hope to earn by signaling plus a little bit, which means for this $c$, no bank would be willing to signal on its own because it could not pass the costs of signalling on to its borrowers. This then is a circumstance where the interbank market will fail because of uncertainty, and private incentives to restart it by signalling will be insufficient. ${ }^{25}$

It turns out that if government pays to acquire the information on banks risk exposures, it can improve the function of the interbank market and create social surplus in some circumstances when the market fails. ${ }^{26}$ To illustrate, suppose one bank has default probability $P_{H}$ and the other $2 N-1$ have default probability $P_{L}$, i.e. suppose that the worst case beliefs associated with uncertainty are correct. If the government searched for the one bad bank sequentially, publicized for each bank searched whether it is $H$ or $L$ and announced its risk exposures, and then stopped after the bad bank was found, its expected search costs are $(2 N-1) c / 2 .{ }^{27}$ After the bad bank is located and its presence is announced, then the other $N-1$ low risk borrower-banks can borrow in the interbank market and then extend short-term loans. Across all $M$ subperiods, assuming the high risk bank is shut, leaving

\footnotetext{
${ }^{25}$ If information is gathered, $P_{L}$ is the lowest possible risk that bank $i$ could possibly have. Since its true $P D$ will be greater, with this information cost the loan will not be extended.

${ }^{26}$ Note that in the present treatment government actions only create surplus by generating information and changing agents beliefs. In Caballero and Krishnamurthy (2008), government actions create surplus through an additional channel: welfare is measured relative to beliefs of a benevolent social planner, rather than relative to the beliefs of the agents in the model. We rule out this additional channel in our analysis.

${ }^{27}$ Because the banks are identical based on observable characteristics, this search strategy is optimal.
} 
one bank without an ability to fund its short-term loans, manipulation of equation 17 shows this will generate loans with surplus $2(N-1)(c-\epsilon)$ before information costs. Which means that after expected search costs, the social surplus generated by the government information provision is on the order of $N c>0$, showing government sponsored sequential search and release of information can improve social welfare and the functioning of the interbank market in some circumstances when private incentives are insufficient. The same logic applies if the government's costs of revealing information are higher than that of the private sector; and as we show below there are special circumstances in which the surplus generated by government action can be arbitrarily large.

These results are formalized in the following proposition.

Proposition 4 There exist $P_{H}, P_{L}, N, M, c, L G D_{i}$ and $\bar{R}_{l}$ such that:

1. Because of uncertainty about banks risk exposures the interbank market may break down.

2. Private provision of information on the exposures may be too costly to restart the market.

3. Sequential government-supported inspections in which the government inspects banks, and announces their health and risk exposures may restore market functioning and improve social surplus. This may be possible even if the government faces higher costs of information gathering than the banking sector faces.

4. There are parameter values for which results 1 - 4 hold, and for which the expected social surplus from sequential government-supported inspections can be made arbitrarily large.

Proof: See the appendix.

Public provision of information is welfare enhancing because when public search for bad banks succeeds, the knowledge of its positions and the outstanding assets $Y_{M}$ allows banks to update their assessment of the worst-case risks in the anonymous brokered market, reducing economy-wide uncertainty, and creating an external benefit. As parameterized, for the expected external benefit to be positive, the government's search activity has to stop before every bank is examined because if every bank is examined the costs of searching would just be equal to the total private search costs, and the total surplus would be negative, as it is in 
the private case. Because on average the government only has to search in half of the banks, government search is welfare enhancing. ${ }^{28}$

The proposition is proved in the special case where worst case beliefs on asset exposures and the exposures coincide. In a more general setting, the worst case beliefs will be the same, but the actual asset exposures will differ, and consequently the surplus will depend on the audit strategy, asset allocations, and the government's rule for when to stop auditing. To analyze these issues, I used simulations to study how the distribution of risky assets across banks affects the surplus calculation. I chose a nonoptimal search rule in which the government searches for risky asset exposures one bank at a time, and stops searching when the market restarts and surplus is at least $40 \%$ of what it would be if the risky assets were evenly dispersed. Experience shows this rule generates more surplus than just searching until the interbank market restarts. It is also important not to audit too many banks because search is costly.

\section{Simulation Analysis}

In the simulations there are 2 assets (sectors), and $c, 2 N, R_{l}$, and the aggregate exposure vector of core banks $Y_{M}$, are such that the worst case beliefs about $P_{H}$, and $P_{L}$ satisfy the properties in proposition 4. This means $\widehat{P D}(A B M)$ is such that the interbank market breaks down initially, and $c$ is such that the surplus would be as in the proposition if the most pessimistic beliefs were actually consistent with the true allocation of risky assets among the banks. ${ }^{29}$ There are $2 N=20$ banks that are ex-ante identical, but their portfolios are tilted by different amounts toward the high risk asset (asset 2), which can be interpreted as the high-risk real-estate sector. In particular, each bank's portfolio weight in risky asset $2, w_{2}$, can range from 0.4 to 0.6 , and its weight in asset 1 is $1-w_{2} \cdot{ }^{30}$ Given the asset supplies, there is a $2 N \times 2$ matrix of portfolio weights $W_{d}$ (with the first and second columns corresponding to weights in assets 1 and 2) in which the holdings of asset 2 are maximally dispersed (all banks hold the same amount of asset 2), and a second matrix $W_{c}$ in which the holdings of asset 2 are maximally concentrated (one bank has portfolio weight $w_{2}=0.6$, and the others

\footnotetext{
${ }^{28}$ It would of course be trivial to create examples where the government faces lower costs of signalling bank quality than the banks themselves. This could occur, for example, if the banks' attempts to signal their own quality are not credible, but that government signals are credible.

${ }^{29}$ For simplicity, $\epsilon$ in the proof of the proposition is set to 0 .

${ }^{30}$ The book value of each banks long-term asset portfolio is normalized to $1(A=1)$. In addition, $R^{D}=1.03$, assets 1 and 2 have standard deviations of return conditional on $I_{1}$ given by .015 and .06 , and the assets returns have correlation 0.3. For any simulations in which the bank defaults and becomes insolvent, the loss given default experienced by its short-term lenders is $50 \%$. The expected returns $\mu(1)$ on assets 1 and 2 were allowed to differ depending on economic conditions.
} 
have $\left.w_{2}=0.4\right) .{ }^{31}$ The simulations are conducted for matrices of portfolio weights $W(\lambda)$ that are convex combinations of the maximally dispersed and maximally concentrated holdings:

$$
W(\lambda)=\lambda W_{c}+(1-\lambda) W_{d}, \quad \lambda \in[0,1],
$$

where $\lambda$ can be interpreted as a concentration index that ranges from 0 (maximally dispersed) to 1 (maximally concentrated). For each matrix, the government's inspections are random searches that stop when the surplus created from the government's actions is high enough, as discussed above. To estimate the expected surplus generated for each matrix, 10,000 random searches are conducted, and the average surplus generated net of search costs is reported.

The simulation results shows that the expected surplus of search is increasing in the concentration of bad assets (Figure 3), which is sensible since less concentration requires more costly audits to restart the markets. An assumption in the analysis is that the government's audit costs are equal to the bank's signalling costs. The government's audit costs could be higher because banks have more expertise in analyzing bank assets. Or, the government's audit costs could be less because the banks signals of their own quality may be viewed as less credible than signals provided by the government. To analyze the importance of cost differences, the surplus calculations were repeated when the government's audit costs are 1 to $3 x$ the bank's signalling costs. The results show the surplus is sometimes positive, but for a very broad range of concentration and costs the expected surplus is negative (Figure 4).

One of the reasons the surplus is negative is that government search is completely random, as if the government has no prior information about banks relative exposures to the distressed asset class. If we pretend bank inspectors have better information about banks relative risk exposures, then using that information has a dramatic effect on the surplus calculations. In particular, under the strong, but not unrealistic assumption that government knows the ranking of banks exposures to the distressed asset class, inspecting banks by ranking has a major effect on the surplus calculations, generating positive surplus for a very wide range of concentrations, and even for high government search costs (Figure 5). It is also important to add that other distortions that are not consider here such as banks using credit rationing when making short-term loans, may prevent banks from capturing surplus, that the government's audit policy would also capture.

\footnotetext{
${ }^{31}$ Note: in these simulations I have relaxed the assumption that one bank can hold all of the high risk asset in its portfolio since that assumption is not essential. For comparability purposes with proposition 4 , the condition I did maintain is that $Y_{M}$ is such that worst case beliefs involve one high risk bank and $2 N-1$ low risk banks.
} 
In addition to the simulations with dispersed asset holdings, I have also generalized proposition 4 to allow more than one bank to have a high default probability, while the others to have a low default probability. When there are $2 N=20$ banks and up to five banks have a high probability of default, the results in the proposition generalize. It generalizes for some situations when $N$ is larger, but they have to be checked by simulation or very tedious combinatorics so I have not done a complete analysis. ${ }^{32}$ When $2 N=20$ if for worst case beliefs the number of high risk banks exceeds 5, the expected number of random searches required becomes too large to generate positive surplus.

In closing this subsection, it is useful to compare the government intervention on information release policy proposed above with past historical interventions that provided information on bank health. Park (1991) found that the Bank Holiday of (1993), which temporarily closed banks, and only reopened those deemed solvent, and earlier experiences with bank clearinghouse's that issued clearing loan certificates during a crisis both improved market functioning because it provided the public with information about the quality of bank assets, which allowed them to distinguish between solvent and insolvent financial institutions.

More recently, the Supervisory Capital Assessment Program (SCAP) in the United States has been perceived as having led to an easing of credit conditions because it also provided a clearer picture of bank's financial health by subjecting banks portfolios to stress tests, and then releasing the results of the exercise.

One of the findings revealed by the stress-tests was that within the pre-crisis categorization of loans for regulatory reporting purposes, there were significant differences in loss rates within asset categories $^{33}$ :

"For example, while the median two-year loss rate on first-lien mortgages was 8 percent across the 15 Bank Holding Companies (BHCs) with a material amount of mortgages, the rates varied from a low of 3.4 percent to a high of nearly 12 percent. For second and junior lien mortgages, the range among 14 BHCs was 6 percent to 21 percent, and a median rate of about 13 percent. Such variation reflects substantial differences in the portfolios across the BHCs, by borrower characteristics such as FICO scores, and loan characteristics such as

\footnotetext{
${ }^{32}$ To prove the result for $2 \mathrm{~N}=20$, I assumed the government searched until all bad banks were found, and computed the expected number of searches required using Monte Carlo analysis. The other parts of the proof are similar to the proposition.

33 "For the most part [in the SCAP exercise], these categories [for assets] are based on regulatory report classifications to facilitate comparison across BHCs and with information reported by BHCs in their regulatory filings [The Supervisory Capital Assessment Program: Design and Implementation (2009), page 8]."
} 
loan to value ratio, year of origination, and geography. These differences result in significant variation in loss estimates at the firm level as compared with applying a single loss rate per asset category to all BHCs. ${ }^{34}$

The differences in loss rates across the categories show that the categorization of risk exposures that may have provided sufficient certainty pre-crisis, may have been too coarse when economic conditions deteriorated. In this interpretation, the contribution of the stress test is that it revealed information on banks risk-exposures to subcategories of loans that varied by borrower quality. This helped reduce uncertainty over who was exposed to what, and helped bring down borrowing spreads.

In sum, theory and past experience both show there may be a need for government to occasionally step in and improve the quality of information in markets. There is also a case for encouraging the development of market institutions that reduce the effects of uncertainty ex ante. In the next subsection I discuss how the structure of the Fed Funds market serves that role, and then in the following subsection I discuss the role for government to further reduce uncertainty in that market.

\subsection{Uncertainty, Information, and the Structure of the Interbank Market}

This section studies why the interbank market has a multi-tier structure with the features that small banks do not borrow in the anonymous brokered tier of the market, but can engage in relationship borrowing arrangements with large banks. ${ }^{35}$ A fully formal analysis is beyond the scope, of this paper, but an informal analysis follows. In the analysis small banks are added to our basic framework, and then it is extended in four ways.

First, small (S) and large (L) banks have a signalling technology, which if costs $C(S)$ and $C(L)$ are paid, perfectly reveal the bank's portfolio composition. At date 1, banks that receive a signal pay a one-time cost $e(S)$ and $e(L)$ to analyze another bank's signal. Because large banks are usually more complex than small banks, $C(L)>C(S)$; and $e(L)>e(S)$. I assume banks can choose to pay these costs and signal at the start of date 1 just after information has arrived.

\footnotetext{
${ }^{34}$ The Supervisory Capital Assessment Program: Overview of Results (2009), page 10."

${ }^{35}$ Although small banks are net lenders in the Federal Funds market, Furfine (199) finds that they are not excluded from borrowing in the market.
} 
Second, the choice of counterparties in the anonymous brokered market is modelled explicitly. In particular, trading in the anonymous brokered market is modelled as a multi-stage game. The first stage occurs at date 1, after banks have signalled or not. In this stage each small and large bank provide the broker with a list of banks to whom it is willing to lend in the anonymous brokered market. Which banks are included on these lists is a part of the equilibrium. For simplicity these lists are treated as public information.

Third, competition in the interbank market is modeled as a Bertrand game with price discreteness. This assumption allows lending banks to earn a small amount of economic rents from borrowing banks, and helps to pin down the equilibrium in the market.

Fourth, the bilateral and anonymous brokered markets are modeled jointly. In particular, after the first stage at date 1 , the second stage occurs. In the second stage, there are M subperiods of trade. In each subperiod, small and large banks are hit with funding and lending shocks of equal size. Then, banks trade with each other in the bilateral market, and then in the anonymous brokered market. In the bilateral market, trade can occur when a lending bank is uncertain about a borrowing banks portfolio, or if the borrowing bank has signaled, trade can occur in an environment of full information. Also, in the bilateral market, I allow for the possibility that a lending bank may not have the funds to immediately advance to a borrowing bank. However, the lending bank can borrow in the anonymous brokered market and then advance the funds to the bank. In the anonymous brokered market, banks submit orders to borrow and lend to the broker, and for each order to borrow, the broker randomly matches it with one of the lending banks that has that borrower on its list. The borrower offers a price; and the lender decides whether to accept or not. If a borrower is declined; the broker throws his order back in the pool of borrowers and he can borrow again in the subperiod if selected. Unlike borrowers, lenders are modeled as being unable to lend again within a subperiod if they turn a borrower down, but they can invest their excess funds from a subperiod at the risk-free rate until date 2. The assumptions on what occurs if a borrowing bank is declined gives substantial bargaining power to borrowing banks, and makes the market a "borrowers market" in which borrowing banks extract all surplus from lending banks other than the profits lending banks earn because of price discreteness. For simplicity, I assume that in the bilateral market if signalling occurs to two or more banks then lending bank also have all of their rents competed away other than those that are associated with price discreteness. ${ }^{36}$

\footnotetext{
${ }^{36}$ In reality lending banks may be able to extract additional rents because borrowing banks want to avoid the signal evaluation costs that would be associated with switching lenders.
} 
The extended framework is used to answer the questions:

1. Why are small banks excluded as borrowers from the anonymous brokered market?

2. Why is there relationship borrowing in the bilateral market?

The answer to the first and second questions are best explained in the context of the example with two risky assets that was presented in section 3.3. To build on this example, suppose that in addition to the $N$ large banks that receive lending shocks and attempt to borrow in the anonymous brokered tier of the interbank market there are are also $S$ small banks, $s=1, \ldots S$, that could attempt to borrow in the top tier of the market. For simplicity, the small banks have identical observable characteristics that only differ from the large banks in the size of their assets $\left(A_{s}<A_{k}\right)$. In this case the worst case probability of default in the brokered market is given by:

$$
\widehat{P D}(A B M)=\begin{aligned}
& \max _{\substack{\omega_{k}, k=1, \ldots 2 N-1 \\
\omega_{s}, s=1, \ldots S}} \frac{1}{2 N-1+S}\left(\sum_{k=1}^{N} P D_{k}\left(\omega_{k}\right)+\sum_{s=1}^{S} P D_{s}\left(\omega_{s}\right)\right) \\
&
\end{aligned}
$$

subject to the constraints that:

$$
\sum_{k=1}^{2 N} \omega_{k} A_{k}+\sum_{s=1}^{S} \omega_{s} A_{s}=\tilde{Y}_{M}
$$

and for each $k$ and $s$,

$$
\omega_{k} \in(\underline{\omega}, \bar{\omega}) \quad \omega_{s} \in(\underline{\omega}, \bar{\omega})
$$

and where

$$
\sum_{s=1}^{S} A_{s} \bar{\omega}_{s}[1]<<\tilde{Y}[1]
$$

In the above maximization, $\tilde{Y}_{M}$ is the vector of loans that are supplied by large and small banks collectively. As earlier, we assume that banks know the total supply, but do not know which banks are exposed to which loans. The last condition implies that the size of the small banks collectively is much smaller than the amount of loans that have been made to sector 
1 , which is a sector of the economy whose loans are expected to perform poorly conditional on date 1 information.

Because each bank's probability of default is increasing in the amount of assets it holds in sector 1 , because of the convexity of the maximization problem (18), from the proof of proposition 1, it follows that the portfolio weights which maximize $\widehat{P D}(A B M)$ set $\omega_{s}[1]=$ $\bar{\omega}[1]$ for small banks $s=1, \ldots S$, and then allocates all remaining holdings of asset 1 , to a single large bank. As in the two asset example, the other large banks concentrate their asset holdings in asset 2 . To analyze how including small banks in the anonymous brokered tier of the interbank market affects robust default probabilities versus the case when they are not included, note that in the worst case beliefs with small banks, each small bank has a greater portfolio weight on asset 1 than the maximal feasible weight on asset 1 when only large banks were present. Therefore, in the worst case beliefs, each small bank has default probability $P_{S}$ with $P_{S}>P_{H}$ (where $P_{H}$ is from equation 16). On the other hand, the large bank that has an exposure to asset 1 , now has default probability $P_{H}^{\prime}$ where $P_{H}^{\prime}<P_{H}$. Therefore after the inclusion of the small banks in the two-asset example, the worst-case PD is equal to $\frac{S P_{S}+P_{H}^{\prime}+(2 N-2) P_{L}}{2 N-1+S}$. From this expression, algebra shows that provided $N$ is greater than 2 (which is required for an anonymous brokered market to make any sense) and $S>2$ (which is realistic) allowing the small banks to participate as borrowers in the anonymous brokered market increases the worst-case probability of default. This result is summarized in the following proposition

Proposition 5 If there are 2 or more small banks and two or more large banks that want to borrow in the anonymous brokered tier of the interbank market, then if $\sum_{s=1}^{S} A_{s}<<\tilde{Y}[1]$, then the worst-case probability of default for the two asset example in equation 18 is increasing in the percentage of small banks that participate in the anonymous brokered tier of the market.

\section{Proof: See the appendix.}

Although proposition 5 is specific to the two-asset example, the result that allowing small banks to borrow in the ABM increases worst case probabilities of default is more general, and is driven by two effects. ${ }^{37}$. The first effect, "the many small banks effect", is that many small banks can hold a high risk portfolio while still satisfying the resource constraint (equation 14). Therefore, the inclusion of small banks increases the worst case probability of default by increasing the fraction of banks in the interbank market that could have the highest possible risk.

\footnotetext{
${ }^{37}$ The more general result is available from the author upon request
} 
The second effect, "the diversification effect" is that small banks by virtue of their size can hold portfolios that are less diversified than a large bank could hold. For example, if there is a problem in a "small" 1 billion dollar sector of the economy, then a large bank by virtue of its size (say 400 billion dollars or more) might only be capable of having a small portfolio weight in that sector. Conversely, many small banks may be able to have a high portfolio weight in the distressed sector - and therefore many small banks can have a high probability of default when beliefs are worst case. To formally model the diversification effect, the analysis would have to account for differences in large and small banks abilities to obtain particular portfolio exposures, which goes beyond the scope of this paper.

The result of proposition 5 shows why small banks who have not signalled as borrowers can increase $\widehat{P D}(A B M)$ for a bank that chooses to list small banks as potential borrowers in the anonymous brokered market. Building on proposition 5, I show that there are equilibria of the extended model in which large banks choose to exclude small banks from their lists of borrowers in the ABM. To establish the equilibrium result, suppose first that all large banks exclude small banks from their lists. In the proposed equilibrium, large banks that make interbank loans earn rents from the banks that they lend to, and large banks that lend to short-term borrowers also earn positive rents. To show that the proposed equilibrium is an equilibrium it suffices to show that no large or small bank would gain from deviating.

One form of deviation is that a large bank could add a small bank to his list. If he added small banks to his list who had not signalled, this would raise his $\widehat{P D}(A B M)$ and his reservation spread, but in a borrowers market, borrowers will not offer a higher spread because they know brokers will eventually match them with a bank that offers lower spreads. Thus the lender who listed small banks who had not signalled would earn lower profits than if he had not deviated. ${ }^{38}$

On the other hand, if a large bank added small banks to its list who had signalled, then small banks who were lower risk than the spreads among large banks in the ABM would not want to participate in the ABM since they could earn lower spreads if there is enough potential competition in the bilateral market. This means only small banks with a relatively high $P D$ would choose to borrow in the ABM, but large banks would not include them on their lists because it would price them out of the market, as explained above. Thus small banks are excluded from the ABM as borrowers. ${ }^{39}$

\footnotetext{
${ }^{38}$ More formally, because the source of the rents is price discreteness, if the prices that can be quoted are fine enough, then the lender with a higher $\widehat{P D}(A B M)$ would be undercut most of the time.

${ }^{39}$ This is consistent with empirical analysis that small banks ability to borrow in the Fed Funds market is constrained [Ashcraft et. al. (2009)].
} 
Note, the reasoning above on the exclusion of small banks as borrowers from the anonymous brokered market assumes that all banks that want to borrow in the ABM (and appear on a large banks list of borrowers) are chosen for a loan with equal probability in the anonymous brokered market irrespective of their size. If large banks could choose the optimal matching probabilities while explicitly conditioning on the size of different borrowing banks, then the large banks optimal matching rule would not exclude small banks from the brokered market, but it would severley downweight the probality that small banks would receive loans. In particular, analysis that will appear in the appendix shows that when borrowing banks have two asset sizes, either large or small, then lending banks would optimally choose a matching probability for each bank that is equal to that banks assets divided by the sum total of all banks assets. Because in the US small banks are much smaller than large banks, this matching, this matching rule allows each small bank to receive a loan only with a very small probability, that is nearly zero. If there is a small fixed cost of participating as a borrower in the anonymous brokered market, then given the low odds that small borrowers would be matched with other banks, it is not surprising that they don't participate as borrowers in the anonymous brokered market, especially given the low cost alternative of small banks signaling their quality.

A different type of deviation is that a large bank could signal its quality and attempt to borrow in the bilateral market. If signalling costs are high for large banks, as seems reasonable, many large banks will not be able to do this, and will instead prefer to borrow in the brokered market. In reality large banks differ in their size and signalling costs. This suggests that some large banks that are relatively small be able to signal and then borrow at a low cost — while many others will not signal but will borrow in the brokered market.

This leave open the question of where small banks could lend and borrow. Regarding lending, the analysis suggests that small banks would prefer to lend in the anonymous brokered market for the same reason that large banks would. They often do this in reality, albeit through correspondent banking in which a large bank does the transaction on their behalf in the brokered market. ${ }^{40}$ Regarding borrowing, the analysis suggests small banks would need to borrow in the bilateral tier of the market - and would have to signal to avoid paying an uncertainty premium. Because signal evaluation is cosly, and some of the incidence of the cost of signal evaluation would fall on small banks, each small bank would prefer relationship loans that involve borrowing from one or a small number of lenders. ${ }^{41}$

\footnotetext{
${ }^{40}$ The small bank does not borrow from the large bank acting on their behalf as part of this transaction.

${ }^{41}$ Relying on a small number of lenders increases evaluation costs, but creates competition among potential lenders.
} 
In sum, the analysis for the extended model shows that the multi-tiered structure for borrowing in the interbank market is an equilibrium. In that equilibrium, because signalling is costly for large banks, they trade with each other in the brokered market. This avoids information costs, but keeps uncertainty premia low because of anonymous matching, and also because small banks are excluded as lenders from the brokered market. For small banks, whose costs of signalling are lower, they choose to borrow on a relationship basis.

The spreads that large banks pay each other in the anonymous brokered market depends on both the number of large banks trade in the brokered market, and on the types of assets that get shocked. To analyze the role of each, first consider the role of the number of core banks. Bech and Atalay note that in 2006 banks in the center of the Fed Funds market received funds from 19.1 banks on average and lent funds to 9.3 banks on average. These average numbers can be misleading because the distribution is very skewed. For example, the most active bank in the center received funds from 127.6 banks in 2006, and lent funds to 48.8 banks. This shows the number of banks that are potentially on the other side of trades in the anonymous brokered market is large. The effect of such a large $N$ can be illustrated from the two asset example. When the bad asset can be absorbed by one large bank, then $\widehat{P D}(A B M)=P_{L}+\frac{1}{2 N-1}\left(P_{H}-P_{L}\right)$. As $N$ grows large, with $Y_{M}$ fixed, this expression approaches $P_{L}$, which means that a large number of large banks interacting anonymously in the brokered market leads to low spreads when the bad asset (asset 1 in the example) is in one small sector that (with worst case beliefs) can be absorbed by one bank. Suppose instead asset 2 was severely affected and core banks total exposures is much greater than any banks ability to absorb it on its balance sheet $Y_{M}[2]>>A_{k}$. Then worst case beliefs imply that many banks $(J>1)$ may have a large exposure to asset 2 , which implies a much larger value for the worst case probability of default: $\widehat{P D}_{i}=P_{L}+\frac{J}{2 N-1}\left(P_{H}-P_{L}\right)$, and a market that is more prone to collapse due to uncertainty. In practical terms, this analysis means the anonymous brokered tier of the interbank market may be resilient to problems by a major firm (such as WorldCom, GM, or Chrysler), but it may be less resilient when a severe shock hits a sector that many banks are exposed to, such as housing.

\section{Summary}

In summary, this section has shown that the two-tier structure of the Fed Funds market, and who participates in each tier, helps to reduce the effects that uncertainy about banks positions have on interbank spreads. In particular 
- If small banks and large banks participate as borrowers with large banks in the top tier of the interbank market, and if all are matched for borrowing with equal probability, then the small banks participation increase uncertainty premia through a "many small banks effect" and through a "diversification effect". For this reason, small banks do not participate as borrowers in the top tier of the market. If matching probabilities in the brokered market are conditioned on banks size in equilibrium, then small banks would be matched with very low probability, and would probably prefer signaling instead and borrowing in bilateral markets.

- When small banks borrow in the interbank market, they do so on the basis of relationship loans from a small number of lenders.

- Many large banks participating in the top tier of the interbank market reduce uncertainty premia, especially uncertainty regarding exposures to small sectors of the economy.

- The top tier of the interbank market can generate significant uncertainty premia when sectors to which many large banks must have exposures suffer.

The next section discusses how the government's role in shaping the set of publicly available information can further reduce information premia.

\subsection{Role for government in shaping prior information}

The model suggests two informational roles for government policy. The first is to provide information that helps to resuscitate markets when they collapse. The second is to shape the information environment to improve market function and reduce the likelihood of future collapses. To illustrate the role for shaping the information environment, consider again the problem of solving for worst case beliefs in equation 13, but suppose banks' information on $Y_{M}$, the vector of core banks asset holdings is coarsened. In particular instead of observing $Y_{M}$, banks only observe $\tilde{Y}_{M}$, which equals $Y_{M}$ plus a positive noise vector $\epsilon_{B O}$. Banks information may be coarser than $Y_{M}$ if published banking statistics do not separately report core banks exposures, or if available information on core banks is not detailed. The coarsened information changes the constraint in equation 14 to

$$
\sum_{k=1}^{2 N} \omega_{k} A_{k}+\epsilon_{B O}=\tilde{Y}_{M}
$$


The coarsening relaxes constraints in solving for worst case beliefs. For example, if a high value of $\tilde{Y}_{M}[1]$ is reported, worst case beliefs might erroneously conclude that core banks exposures to asset 1 are greater when in fact non-core banks exposures are actually greater. The result is more precise information on core-banks asset holdings $Y_{M}$ reduces uncertainty premia, and more coarse information makes it worse. This is stated formally below:

Proposition 6 When the information on core banks total asset holdings $Y_{M}$ is coarsened as in equation 20, then, all else equal, worst case beliefs about core banks probability of default increase, and uncertainty premia increase as well. Less coarse information about $Y_{M}$ has the opposite effect.

Proof: Obvious because coarser information about $Y_{M}$ relaxes a constraint in the optimization problem 13 that solves for worst case beliefs regarding default probabilities. $\square$.

Two corollaries follow immediately:

Corollary 1 If banks are uncertainty averse, then all else equal, coarser information on $Y_{M}$ increases the likelihood that markets will collapse because of uncertainty.

Proof: Straightforward since interbank lending collapses when spreads become high enough.

Corollary 2 If banks are uncertainty averse, then all else equal, coarser information on $Y_{M}$ will increase the cost of using sequential government inspections to restart interbank markets that collapsed.

Proof: If the information is coarser, then after the government inspects a bank, and reveals information on its exposures, the worst case PD of the remaining banks will be higher because coarser information relaxes constraints on their worst case PD. Therefore, the number of searches required to reduce spreads enough to restart markets will be greater. $\square$

Corollaries 1 and 2 together show that if banks are uncertainty averse, then precise information on $Y_{M}$ helps to reduce fragility ex-ante, and if collapses occur, to reduce the costs of restarting interbank markets ex-post. 
The proposition and corollaries both have the qualifier "all else equal" because individual banks may respond to a coarsening of information on $Y_{M}$ by improving the quality of their own information disclosures, which could reduce the size of the set $\mathcal{C}(\underline{\omega}, \bar{\omega})$. Several institutions did in fact belatedly improve the quality of their disclosures during the global financial crisis of 2007-2009. The question is whether private incentives are sufficient for resolving these informational problems, or whether there is a role for government in improving disclosures. Because of informational externalities private incentives to provide information on $Y_{M}$ may be inadequate. This is especially true during good times because information premia may be very small if times are good enough. For example, consider again the two asset example as parameterized for the simulations in section 3.3. ${ }^{42}$ Figure 6 plots spreads over the riskfree rate as a function of $Y_{M}[2]$ the supply of asset 2 held by core banks, when information at date 1 shows its expected returns are high. In a departure from earlier analysis in the paper, spreads are presented not just for the worst case beliefs about banks asset holdings under Knightian Uncertainty, but for all beliefs about bank's portfolio's that are possible conditional on $Y_{M}[2]$ and support a pooling equilibrium in the brokered market. The analysis shows that for all beliefs that are possible, interbank credit spreads never exceed $1 / 2$ basis point regardless of $Y_{M}[2]$. In these very good conditions, incentives of banks to reveal information on $Y_{M}$ is low. ${ }^{43}$

The analysis in this paper points towards two potential types of transparency policies pre-crisis. The first is policies that improve knowledge of individual core banks risk exposures ex ante. In the paper uncertainty about individual banks risk exposures is modeled via the condition that each bank believes other banks risk exposures lie within a set: $\omega \in \mathcal{C}[\underline{\omega}, \bar{\omega}]$, but the paper does not specify precisely where the set comes from (although it is motivated by near optimal behavior). Part of enhanced disclosure could be release of information on risk limits on exposures to different types of assets. Enhanced risk limit information refines the size of the set $\mathcal{C}[\underline{\omega}, \bar{\omega}]$, but need not reveal a banks precise risk exposures. In addition, enhanced disclosure would reveal the size of $Y_{M}$ among core banks. These disclosures together would enhance banks ability to form more precise worst case beliefs, which would have the effect of reducing uncertainty premia. In addition, these disclosures, if made before a crisis, may prove helpful during a crisis. For example, if during a crisis, spreads are based on worstcase beliefs, and banks are perceived to be in terrible shape, massive injections of capital

\footnotetext{
${ }^{42}$ In the example there are 20 banks who each have assets normalized to 1 . Because the minimal portfolio weight in asset 2 is 0.4 and the maximal weight is 0.6 , the smallest amount of asset 2 that the 20 banks can collectively hold is 8 , while the maximum amount is 12 .

${ }^{43}$ The best beliefs are found by choosing allocations to minimize $\widehat{P D}_{i}$. The minimum is attained when one bank has a high risk portfolio and is lending in the market, and the other banks all hold the same diversified portfolio.
} 
may be needed to have the desired effect on spreads. To illustrate, we return to the two asset example, but instead of the good times in Figure 6, conditions are weak and the size of $Y_{M}[2]$ can cause interbank spreads to range from 200 basis points when $Y_{M}[2]$ is 10 to as much as 380 basis points if it is perceived to be 12 (Figure 7). In these circumstances if because of uncertainty $Y_{M}[2]$ spreads are set as if it is 12 when it is 10, to reduce interbank spread to 40 basis points requires 82 percent capital injections for all core banks. If instead before the capital injections, information was provided that $Y_{M}[2]=10$, this ex-ante information provision action alone would reduce the required injection to 60 percent. If in addition, the government inspected all banks before capital was injected, then the injections could be better tailored to individual bank needs, which in some cases could reduce the total amount of equity capital that needed to be injected by 50 percent. ${ }^{44}$ In sum, these results show that enhanced transparency before a crisis can reduce the costs of crisis if they occur.

In all of the above analysis, banks are only linked to each other by holding similar assets, but not through any other linkages. Yet, how the banks are linked to each other, which I refer to as the financial architecture, is important. This is discussed in the next section.

\section{Financial Architecture}

The analysis to this point has been predicated on the idea that uncertainty about a bank's insolvency risk is primarily caused by uncertainty about the risk exposures of its long-run asset portfolio, while abstracting from uncertainty about its risk exposures that are associated with other obligations. This is a reasonable approach if the other obligations are small relative to the long-run asset portfolio, but is less tenable when the exposures from those other obligations are sufficiently large. This section briefly discusses how OTC derivatives exposures and interbank exposures affect the analysis.

To analyze the role of OTC derivatives, note that banks can use the OTC derivatives market to hedge their risk exposures or take on more risk. Recall also that at date 0 banks choose their long-run portfolios subject to regulatory leverage and credit value-at-risk

\footnotetext{
${ }^{44}$ For example, when $Y_{M}=10$ worst case asset holdings for interbank spreads would imply that 10 banks need 82 percent capital injections, and 10 don't need any injections. Thus the information would reduce the required equity injections by 50 percent relative to the case when $\tilde{Y}_{M}[2]=14$ and the government did not engage in information gathering. However, the asset holdings associated with worst case interbank spreads in a pooling equilibrium are not necessarily those that require the largest capital injections. For example, when $Y_{M}=10$, the asset holdings that generate the best case interbank spreads require a 62 percent capital injection per bank to bring interbank spreads down to 40 basis points.
} 
constraints, as well as to internal constraints. The internal constraints may cause banks to have too much exposure to some sectors, and too little to others. If banks $i$ has too much exposure to the returns within a sector, it may sell part of that exposure forward through an OTC derivative with bank $k$. Bank $i$ 's derivative position is likely to have two effects on uncertainty. First, by relaxing internal constraints it may move bank $i$ 's inclusive of hedging portfolio weights closer to $\bar{\omega}$, which is the optimal portfolio weight in the absence of internal constraints. This in turn may reduce other banks uncertainty about bank $i$ 's portfolio weights. However, at the same time, the OTC derivatives position means that $i$ 's risk exposure vector depends on whether bank $k$ will perform on its obligations in the OTC derivatives markets. If other banks are uncertain about which banks $i$ is using as its OTC derivatives counterparties, then the uncertainty about $i$ 's counterparty risk exposure will contribute to uncertainty over $i$ 's exposure to the sectors, and to uncertainty about $i$ 's probability of default. Counterparty risk exposure's contribution to overall uncertainty can become particularly acute during a financial crisis, as illustrated during the height of the financial crisis of 2007-2009, when concern over whether the insurance company AIG would make good on its derivatives obligations, and uncertainty about the identity of the parties that were relying on AIG for hedging contributed to a freeze in some lending markets in September of 2008.

Because uncertainty over counterparty risk exposures compounds the effects of uncertainty over other risk exposures, failing to address uncertainty over counterparty risk exposures makes it more difficult to address uncertainty over other forms of exposures. In the context of OTC derivatives markets, moves toward clearing standardized OTC derivatives through well capitalized clearing houses, if designed properly, should help to remove uncertainty over counterparty risk, and therefore increase the effectiveness of the ex-ante and expost transparency initiatives advocated in sections 3.3 and 3.5.

In addition to OTC derivatives, structural uncertainty about banks counterparty risk exposures occurs because the full shape of the network connecting banks through their interbank deposits is unknown. In bad times, when the network has the potential to be a source of contagion among banks (Allen and Gale, 2000) then uncertainty about its shape can cause banks to withdraw from markets, creating a market breakdown as in Caballero and Simsek (2010). Transparency policies that make the pattern of interbank linkages during a crisis more transparent, may help to reduce the uncertainty and restart markets, but the precise form that such policies should take remains a topic for future research. 


\section{Conclusion}

When one bank makes a loan to another, the credit risk of the bank that lends funds is related to the risk of the assets on the borrowing banks balance sheet, but because of opaqueness, the creditor bank will be uncertain about the borrowing banks portfolio composition, and thus uncertain about the risks that it faces. Nevertheless, despite the uncertainty, unsecured overnight interbank borrowing and lending is common - and spreads for interbank loans at the top tier of the Fed Funds market is typically low. In this paper, I show that interbank spreads should contain an uncertainty premium related to credit risk, but because of institutional features of the Federal Funds interbank market, the spread can usually be kept low. Nevertheless, market collapses due to uncertainty are possible. In those circumstances, private efforts to restart markets may not be successful — but sometimes government provision of information as advocated in this paper, or the Bank Holiday of 1933 or the recent Stress Capital Tests that were conducted on US banks can help alleviate uncertainty, restart markets, and improve welfare. Our analysis shows that there is scope for governments to step in ex-post to reduce uncertainty, and furthermore that policies which release better aggregate information on core banks that are at the center of the financial system can help reduce uncertainty ex-ante. An advantage of policies that release aggregate information is that it keeps banks individual exposures private, while still providing information that may improve transparency and financial stability. The success of transparency efforts also depends on how banks are linked to each other in the financial system. How to account for these linkages while formulating a transparency policy remains a topic for future research. 


\section{Appendix}

\section{A Derivation and Proof of Proposition 1}

This section of the appendix provides a formal derivation of the return distribution for the loans in each sector of the economy. Section $\mathrm{C}$ of the appendix studies whether the modeling technique that is used to derive a gaussian distribution for portfolios of loans can also generate reasonable default probabilities.

In each sector $m$ there is a continuum of infinitesimal potential long-term borrowers indexed by $\eta_{m} \in\left[0, \bar{\eta}_{m}\right]$. In this expression, $\eta_{m}$ denotes borrower $\eta$ in sector $m$, and $\bar{\eta}_{m}$ is the measure of potential borrowers in sector $m$. The sectors may vary in size - so that for some sectors, such as housing, $\bar{\eta}_{m}$ is very large, while for other sectors, $\bar{\eta}_{m}$ is small. The distinction in sector sizes will not be important for the analysis in the paper until section 3.4. Each borrower $\eta_{m}$ requires 1 dollar of bank financing for a project that returns $r_{\eta_{m}}$ in period 2, where:

$$
r_{\eta_{m}}=\theta_{m}+\gamma_{m} F+\epsilon_{m}+u_{\eta_{m}}
$$

The return depends on a sector-specific constant, $\theta_{m}$, and three independently distributed components. $F$ is normally distributed K-vector that represents news about the macroeconomy. $\epsilon_{m} \sim \mathcal{N}\left[0, \sigma^{2}\left(\epsilon_{m}\right)\right]$ represents news about sector $m$, and is distributed independently of news in sectors $m^{\prime} \neq m$. Finally, $u_{\eta_{m}}$ is a borrower-specific component that is independent across borrowers and distributed uniformly on $\left[0, \bar{u}_{m}\right]$.

The macroeconomic factor can be further decomposed into components $f(1)$ and $f(2)$ :

$$
F=f(1)+f(2)
$$

where $f(1)$ is the best forecast of $F$ conditional on public information $I_{1}$ that arrives at date $1\left(f(1)=\mathrm{E}\left[F \mid I_{1}\right]\right)$, and $f(2)$ represents the error in the forecast which is learned at date 2.

Because $f(1)$ and $f(2)$ are innovations in beliefs about $F$, they have mean 0 , and are 
uncorrelated; for tractability they are assumed to be normally distributed:

$$
\left(\begin{array}{l}
f(1) \\
f(2)
\end{array}\right) \sim \mathcal{N}\left[\left(\begin{array}{l}
0 \\
0
\end{array}\right),\left(\begin{array}{cc}
\Sigma_{f}(1) & 0 \\
0 & \Sigma_{f}(2)
\end{array}\right)\right] .
$$

Each loan that is extended to a borrower in sector $m$ promises to pay back contractually agreed upon principal plus interest $X_{m}$ at maturity, but in the case of default only produces the non-stochastic recovery value $R G D_{m} \cdot{ }^{45}$ The loan defaults if the rate of return on the entrepreneurs project is less than $X_{m}$. For the purposes of this paper, $X_{m}$ is a fixed parameter that is determined by the financial intermediation process for long-term loans. I abstract from its determination because it is not essential for the analysis of the interbank market.

We will make the following additional approximating assumption about the distributions:

Assumption 4 For all values of $F$ and $\epsilon_{m}$,

$$
0<X_{m}-\left(\theta_{m}+\gamma_{m} F+\epsilon_{m}\right)<\bar{u}_{m}
$$

To a first approximation, the assumption can be understood as requiring that the variability in borrowers returns due to the macro factors $F$ and sector specific risk $\epsilon_{m}$ are small relative to the variability due to the borrowers idiosyncratic risk since $\left[0, \bar{u}_{m}\right]$ represent upper and lower bounds of the idiosyncratic return risk. This assumption cannot literally be true because $F$ and $\epsilon_{m}$ are Gaussian random variables, but in appendix $\mathrm{C}$ we show that the returns on loans can be calibrated so that the probability the assumption is violated is approximately $10^{-7}$. For simplicity and tractability we assume that it is true. Under the condition that it is true,

$$
\begin{aligned}
\operatorname{Prob}\left(r_{\eta_{m}}<X_{m} \mid \epsilon_{m}, F\right) & =\operatorname{Prob}\left(\theta_{m}+\gamma_{m} F+\epsilon_{m}+u_{\eta_{m}}<X_{m}\right), \\
& =\operatorname{Prob}\left(\frac{u_{\eta_{m}}}{\bar{u}_{m}}<\frac{X_{m}-\theta_{m}-\gamma_{m} F-\epsilon_{m}}{\bar{u}_{m}}\right), \\
& =\frac{X_{m}-\theta_{m}-\gamma_{m} F-\epsilon_{m}}{\bar{u}_{m}} .
\end{aligned}
$$

From this probability, conditional on $F$ and $\epsilon_{m}$ it then follows by the law of large numbers

\footnotetext{
${ }^{45} R G D_{m}$ stands for the recovery given default in sector $m$. It is not restricted to depend on $X_{m}$.
} 
that for any positive mass of loans in sector $m$, the fraction that default in period 2 is given by the expression on the right hand side of equation A4. Because $F$ and $\epsilon_{m}$ are normally distributed conditional on the information sets $I_{0}$ and $I_{1}$, it then follows that the fraction of loans from sector $m$ that will default in period 2 is also normally distributed conditional on $I_{0}$ and $I_{1}$.

Let a sector portfolio denote a portfolio of loans to a positive mass of borrowers in sector $m$. Because $X_{m}$ and the recovery given default are non-stochastic, the return per dollar to the sector-portfolio, denoted $R_{m}$, is proportional to the fraction of borrowers that default, and is also normally distributed. Additionally, the vector of returns per dollar for loans in each sector, denoted by $R=\left(R_{1}, \ldots R_{M}\right)^{\prime}$, is jointly normally distributed. This result, and the details of the conditional distribution functions is stated formally below:

Proposition 1: Under assumption 4, $R$, the gross return on an M-vector of sector portfolios has the following distribution conditional on $I_{0}$ and $I_{1}$ :

$$
\begin{array}{r}
R \mid I_{0} \sim \mathcal{N}[\mu, \Sigma] \\
R \mid I_{1} \sim \mathcal{N}[\mu(1), \Sigma(1)]
\end{array}
$$

where,

$$
\begin{aligned}
& \mu=\alpha, \\
& \mu(1)=\alpha+\beta f(1) \\
& \alpha=\left(\begin{array}{c}
\alpha_{1} \\
\vdots \\
\alpha_{M}
\end{array}\right), \quad \beta=\left(\begin{array}{c}
\beta_{1}^{\prime} \\
\vdots \\
\beta_{M}^{\prime}
\end{array}\right) \\
& \alpha_{m}=\left[X_{m}+\left(R G D_{m}-X_{m}\right)\left(\frac{X_{m}-\theta_{m}}{\bar{u}_{m}}\right)\right] \text {, } \\
& \beta_{m}=\left[\frac{\left(X_{m}-R G D_{m}\right) \gamma_{m}}{\bar{u}_{m}}\right] \text {, } \\
& \Sigma=\beta\left[\Sigma_{f}(1)+\Sigma_{f}(2)\right] \beta^{\prime}+\left[\begin{array}{lll}
\sigma^{2}\left(\epsilon_{1}\right) & & \\
& \ddots & \\
& & \sigma^{2}\left(\epsilon_{M}\right)
\end{array}\right], \\
& \Sigma[1]=\beta\left[\Sigma_{f}(2)\right] \beta^{\prime}+\left[\begin{array}{lll}
\sigma^{2}\left(\epsilon_{1}\right) & & \\
& \ddots & \\
& & \sigma^{2}\left(\epsilon_{M}\right)
\end{array}\right] \text {. }
\end{aligned}
$$


Proof: See the derivation above the proposition. $\square$.

The proposition is a straightforward application of the law of large numbers and closely follows Vasicek's(2002) development of asymptotic portfolios. However, in Vasicek, the returns on asymptotic portfolios are a nonlinear function of the factors, which is unwieldy for theoretical modeling with even a single factor. By contrast, the derivation here presents a linear result, which is useful for many theoretical modeling applications, including the ones considered here.

\section{B Other Propositions and Proofs}

Proposition 2: Although there is Knightian uncertainty about banki's positions, under some economic conditions (such as case 1), favorable economic news can reduce the loan spread that bank $i$ pays for borrowing in the interbank market even though there is Knightian uncertainty over banki's positions. Conversely, under other economic conditions, such as those in case 2, sufficiently unfavorable news about some sectors of the market can destroy bank $i$ 's ability to finance its new lending opportunities in the interbank market, effectively causing the interbank market to break down.

Proof: Assume $\omega_{i} \in C\left(\omega_{i}^{*}\right)$ maximizes $P D_{i}(\omega, 0)$ the probability that $i$ defaults conditional on information at time 0 , and $\tilde{\omega}_{i}$ maximizes $P D_{i}(\omega, 1)$, the probability that $i$ defaults conditional on the information at time 1. $P D_{i}\left(\omega_{i}, 0\right)>P D_{i}\left(\tilde{\omega}_{i}, 1\right)$ if:

$$
\frac{\frac{L_{i}}{1+L_{i}} R^{D}-\omega_{i}^{\prime} \alpha}{\sqrt{\omega_{i}^{\prime} \sum \omega_{i}}}>\frac{\frac{L_{i}}{1+L_{i}} R^{D}-\tilde{\omega}_{i}^{\prime} \alpha}{\sqrt{\tilde{\omega}_{i}^{\prime} \rho \sum \tilde{\omega}_{i}}} .
$$

Adding and subtracting $\frac{\frac{L_{i}}{1+L_{i}} R^{D}-\tilde{\omega}_{i}^{\prime} \alpha}{\sqrt{\tilde{\omega}_{i}^{\prime} \sum \tilde{\omega}_{i}}}$ to the right hand side and rearranging shows the inequality holds if:

$$
\begin{aligned}
\frac{\frac{L_{i}}{1+L_{i}} R^{D}-\omega_{i}^{\prime}(\alpha+\beta f(1))}{\sqrt{\omega_{i}^{\prime} \sum \omega_{i}}} & >\frac{\frac{L_{i}}{1+L_{i}} R^{D}-\tilde{\omega}_{i}^{\prime} \alpha}{\sqrt{\tilde{\omega}_{i}^{\prime} \sum \tilde{\omega}_{i}}} \\
& +\left(\frac{L_{i}}{1+L_{i}} R^{D}-\tilde{\omega}_{i}^{\prime} \alpha\right) \times\left(\frac{1}{\sqrt{\tilde{\omega}_{i}^{\prime} \rho \sum \tilde{\omega}_{i}}}-\frac{1}{\sqrt{\tilde{\omega}_{i}^{\prime} \sum \tilde{\omega}_{i}}}\right) \\
& -\frac{\tilde{\omega}_{i}^{\prime} \beta f(1)}{\sqrt{\tilde{\omega}_{i}^{\prime} \rho \sum \tilde{\omega}_{i}}}
\end{aligned}
$$


The left hand side of the inequality is positive because $\omega_{i}$ maximizes the default probability at time 0 . By the assumptions of the proposition, $\left(\frac{L_{i}}{1+L_{i}} R^{D}-\tilde{\omega}_{i}^{\prime} \alpha\right)$ is negative, and $\rho<1$. This guarantees that the first expression on the right hand side is negative. Since $\omega_{i}>0$ and $\beta f(1)>0$, the second term on the right hand side is also negative. This establishes the inequality is true, and shows that under some conditions the news at time 1 is unambiguously good.

To show that in the second case the news can be unambiguously bad, note that the risk exposure to asset 1 can be positive and the news about the mean return of asset 1 is negative. It then follows that if the mean on asset 1 is sufficiently low, and the possible exposure is sufficiently high, then the interbank market will freeze up, as claimed in the proposition. $\square$.

\section{Proof of Proposition 3}

To prove proposition 3, I first solve for the worst case default beliefs that any borrowing bank believes any lending bank could have. The formal solution for the worst case beliefs is slightly complicated because it involves solving for the portfolio of the lending bank and the borrowing banks, and ensuring that the borrowing banks have the highest probability of default possible. This generates four special cases, as illustrated below:

Lemma 1 Under assumption 3, the worst case beliefs $\widehat{P D}_{i}$ that solve 13 are given by the following:

If $P D(\bar{\omega}) \geq P D(\underline{\omega})$, then for $m_{u}$ and $\tilde{\omega}$ that satisfy the conditions,

$$
\begin{aligned}
m_{u} & =\max m, \quad m \in\{1, \ldots, 2 N\}, \quad \text { such that } \\
Y_{M} / A_{k} & =m \bar{\omega}+(2 N-m-1) \underline{\omega}+\tilde{\omega}, \\
\tilde{\omega} & \in \mathcal{C}(\underline{\omega}, \bar{\omega}),
\end{aligned}
$$

if $P D(\tilde{\omega}) \leq P D(\underline{\omega})$, then

$$
\begin{gathered}
\qquad \widehat{P D}_{i}(A B M)=\frac{m_{u} P D(\bar{\omega})+\left(2 N-m_{u}-1\right) P D(\underline{\omega})}{2 N-1} ; \\
\text { if } P D(\tilde{\omega}) \geq P D(\underline{\omega}) \text {, then } \\
\widehat{P D}_{i}(A B M)=\frac{m_{u} P D(\bar{\omega})+\left(2 N-m_{u}-2\right) P D(\underline{\omega})+P D(\tilde{\omega})}{2 N-1} .
\end{gathered}
$$


If $P D(\bar{\omega}) \leq P D(\underline{\omega})$ then for $m_{u}$ and $\tilde{\omega}$ that satisfy the conditions,

$$
\begin{aligned}
m_{u} & =\max m, \quad m \in\{1, \ldots, 2 N\}, \quad \text { such that } \\
Y_{M} / A_{k} & =m \underline{\omega}+(2 N-m-1) \bar{\omega}+\tilde{\omega} \\
\tilde{\omega} & \in \mathcal{C}(\underline{\omega}, \bar{\omega}),
\end{aligned}
$$

if $P D(\tilde{\omega}) \leq P D(\bar{\omega})$, then

$$
\widehat{P D}_{i}(A B M)=\frac{m_{u} P D(\underline{\omega})+\left(2 N-m_{u}-1\right) P D(\bar{\omega})}{2 N-1}
$$

if $P D(\tilde{\omega}) \geq P D(\underline{\omega})$, then

$$
\widehat{P D}_{i}(A B M)=\frac{m_{u} P D(\underline{\omega})+\left(2 N-m_{u}-2\right) P D(\bar{\omega})+P D(\tilde{\omega})}{2 N-1} .
$$

Proof: For each borrower bank, the portfolio that maximizes its probability of default maximizes the opposite of a Sharpe ratio given by

$$
\frac{\frac{L_{i}}{1+L_{i}} R^{D}-\omega_{i}^{\prime} \mu(1)}{\sqrt{\omega_{i}^{\prime} \Sigma(1) \omega_{i}}},
$$

when treating $\left(R^{D} L_{i} /\left(1+L_{i}\right)\right.$ as the risk-free rate. Since the Sharpe ratio is a concave function of a portfolio weights, minus the Sharpe ratio is a convex function of the weights. The probability of default depends on $\Phi()$ of the opposite of the Sharpe ratio. Under assumption 3 , the operational part of the $\Phi()$ function is its lower half, which is a convex function. Since convex increasing functions of convex functions are convex, the probability that any bank defaults is a convex function of its portfolio weights. Since the objective function being maximized is a positive weighted sum of convex functions, it is also a convex function. Inspection will also quickly reveal that the feasible set of portfolios is a convex set. When a convex function is maximized over a convex set, the solution is at the extremes. This implies that no more than one of the $2 N$ banks can have a portfolio weights that are not equal to either $\bar{\omega}$ or $\underline{\omega}$ since if two banks had portfolios in the interior of the set, they would be able to alter their portfolios until one of them hit a boundary. Finally, after the optimal portfolio weights are found, the worst case beliefs that a lender could have would involve a lender having the lowest risk possible, and the borrowing banks having the highest risk possible. Applying this 
criterion generates the four conditions in the final result for $\widehat{P D}(A B M)$. $\square$

Proposition 3: Under assumption 3, and the constraints on beliefs from equations (14) and (15), when there is uncertainty, the spreads that banks pay in the anonymous brokered tier of the interbank market are less than or equal to the spreads they would pay when borrowing in the bilateral tier of the interbank market.

Proof: The result follows directly from the lemma, and the discussion above proposition 3 in the text.

Proposition 4 There exist $P_{H}, P_{L}, N, M, c, L G D_{i, j}$ and $\bar{R}_{l}$ such that:

1. 1 Because of uncertainty about banks risk exposures the interbank market may break down.

2. 2 Private provision of information on the exposures may be too costly to restart the market.

3. 3 Sequential government-supported inspections in which the government inspects banks, and announces their health and risk exposures may restore market functioning and improve social surplus. This may be possible even if the government faces higher costs of information gathering than the banking sector faces.

4. 4 There are parameter values for which results 1 - 4 hold, and for which the expected social surplus from sequential government-supported inspections can be made arbitrarily large.

Proof: For simplicity assume all banks with a surplus of funds are ex-ante symmetric, and that all banks with a shortage of funds are ex-ante identical, and that all short-term borrowers have the same reservation rate for borrowing given by $\bar{R}_{l}$. Furthermore, banks assets holdings correspond with those associated with worst case beliefs so that there are $2 N-1$ banks with low default probability $P_{L}$ and one with high default probability $P_{H}$.

If bank $i$ makes a short-term loan and does not reveal information about itself first, then the social surplus that it creates will be negative if $P_{H}$ and $P_{L}$ satisfy:

$$
\operatorname{Surplus}_{i}=\bar{R}_{l}-\left(R^{D}+\left[P_{L}+(1 /(2 N-1))\left(P_{H}-P_{L}\right)\right] L G D_{i}\right)=\eta,
$$

for some small $\eta<0$. 
If the cost of signalling the information to bank $i$ is $c$ given by

$$
c=\left(\bar{R}_{l}-R^{D}-P_{L} L G D\right)\left(1+\frac{M-1}{2}\right)+\epsilon
$$

for some small $\epsilon>0$, then the cost of signalling exceeds the expected benefits that the bank could hope to earn from signalling immediately and making a loan now plus the expected future benefits from having signalled.

To prove results 1 and 2 , choose $P_{H}$ and $P_{L}$ and $L G D_{i}$ such that $1 / 2>P_{H}>P_{L}>0$, and $1>L G D_{i}>0$. Given these choices, choose $\bar{R}_{l}$ so that $\bar{R}_{l}=R^{D}+\left[P_{L}+(1 /(2 N-\right.$ 1)) $\left.\left(P_{H}-P_{L}\right)\right] L G D_{i}+\eta_{i}$ with $-(1 /(2 N-1))\left(P_{H}-P_{L}\right) L G D_{i}<\eta<0$. These conditions guarantee that without signaling the spread charged to bank $i$ will be too high, and will cause the interbank market to breakdown, proving result 1. Choosing $c$ as in equation A8 guarantees that bank $i$ 's costs from signalling exceed its expected benefits, so it will not signal. The same will be true for all banks $i$, proving result 2 .

To prove 3, assume the government performs sequential information collection (i.e. sequential search) in which it looks at each bank, certifies whether it is good, or bad, discloses information about the banks risk exposures, and stops searching after it has found the single bad bank, which is shut down. The expected search costs are equal to $c(2 N-1) / 2 .{ }^{46}$ Abstracting from the integer problem, of the $2 N-1$ good banks, each is expected to be a borrower in the interbank market in $1 / 2$ of the periods $1, \ldots M$; in each period the borrowing bank captures surplus $\bar{R}_{l}-R^{D}-P_{L} L G D_{i}$, for a total expected surplus net of borrowing costs of:

$$
\begin{aligned}
\text { Surplus } & =[(2 N-1) / 2]\left(\bar{R}_{l}-R^{D}-P_{L} L G D_{i}\right) M-[(2 N-1) / 2] c \\
& =[(2 N-1) / 2]\left(\bar{R}_{l}-R^{D}-P_{L} L G D_{i}\right) M-[(2 N-1) / 2]\left[\left(\bar{R}_{l}-R^{D}-P_{L} L G D\right)\left(1+\frac{M-1}{2}\right)+\epsilon\right] \\
& =[(2 N-1) / 2]\left(\bar{R}_{l}-R^{D}-P_{L} L G D_{i}\right)\left(\frac{M-1}{2}\right)-[(2 N-1) / 2] \epsilon
\end{aligned}
$$

The final line of the expression for surplus can be guaranteed to be positive by choosing $\epsilon$ sufficiently small. This establishes result 3 when the government and private sector have the same cost of monitoring. If $c$ for the government is equal to $\psi$ times the private cost of monitoring, for $\psi<2$, it is straightforward to reevaluate expected surplus and show that it will still be positive, completing the proof of result 3 .

\footnotetext{
${ }^{46}$ At most $2 N-1$ searches are needed, and the chance of finding the high risk bank on each search attempt without replacement is $\frac{1}{2 N}$. Elementary calculations then show the expected search cost is as given.
} 
Finally, holding $N$ fixed, but allowing $M$ to approach infinity, with the resulting consequences for $c$, shows from the last equation that there are economies in which the interbank market will break down, private efforts to restart it will fail, and for which the expected social surplus from the governments efforts to restart the market are arbitrarily large. This establishes result 4 . $\square$.

Proposition 5: If there are 2 or more small banks and two or more large banks that want to borrow in the anonymous brokered tier of the interbank market, then if $\sum_{s=1}^{S} A_{s}<<Y_{M}[1]$, the robust probability of default for the two asset example in equation 18 is increasing in the percentage of small banks that participate in the anonymous brokered tier of the market.

Proof: The robust probability of default is increasing if and only if

$$
\frac{P_{H}^{\prime}+(2 N-2) P_{L}+S P_{S}}{2 N-1+S}>P_{L}+\frac{1}{2 N-1}\left(P_{H}-P_{L}\right)
$$

Since $P_{H}^{\prime}>P_{L}$, the inequality will be satisfied if

$$
\frac{P_{L}+(2 N-2) P_{L}+S P_{S}}{2 N-1+S}>P_{L}+\frac{1}{2 N-1}\left(P_{H}-P_{L}\right),
$$

which reduces to the condition

$$
\frac{P_{S}-P_{L}}{P_{H}-P_{L}}>\frac{1}{2 N-1}+\frac{1}{S}
$$

Because $P_{S}>P_{H}$ the left hand side is greater than 1, while since $N$ and $S$ are greater than two, the right hand side is less than 1. $\square$.

\section{Adequacy of the normality approximation}

This appendix illustrates that the Gaussian approximation for the returns of loan portfolios is reasonable.

Recall that when the returns for infinitesimal investors in sector $m$ satisfy equation A1:

$$
r_{s, m}=\theta_{m}+\gamma_{m} F+\epsilon_{m}+u_{s, m}
$$

where $F$ and $\epsilon_{m}$ are independent and gaussian, and $u_{s, m} \sim \operatorname{Uniform}\left[0, \bar{u}_{m}\right]$. 
then for $F$ and $\epsilon_{m}$ that satisfy the regularity condition 4 :

$$
X_{m}-\theta_{m}>\gamma_{m} F+\epsilon_{m}>X_{m}-\theta_{m}-\bar{u}_{m}
$$

the probability that a loan made at rate $X_{m}$ to entrepeneur $s$ in sector $m$, will default conditional on $F, \epsilon_{m}$ is

$$
\operatorname{Prob}\left(r_{s, m}<X_{m} \mid F, \epsilon_{m}\right)=\frac{X_{m}-\theta_{m}-\gamma_{m} F-\epsilon_{m}}{\bar{u}_{m}}
$$

This implies that in a well diversified portfolio, conditional on the information provided at time 0 , the expected proportion of defaults, which is the unconditional probability of default is $\frac{X_{m}-\theta_{m}}{\bar{u}_{m}}$. If the rates on the loans are set competitively at time 0 , then $X_{m}$ should be set so that investors are indifferent between extending this loan or holding the riskfree asset. This implies that $X_{m}$ solves the quadratic equation:

$$
X_{m}\left[1-\frac{X_{m}-\theta_{m}}{\bar{u}_{m}}\right]+\left[\frac{X_{m}-\theta_{m}}{\bar{u}_{m}}\right] R G D=R_{f}
$$

where $R_{f}$ is the gross riskfree rate and $X_{m}$ is the gross interest rate in the sector.

To illustrate whether our approach can be used to generate reasonable default probabilities for one sector alone we solved the model with one macro factor $F$ and without a sector specific shock (which is unecessary to include in the one sector case). The parameters are as follows:

\begin{tabular}{cc}
\hline$\theta_{m}$ & 0.55 \\
$\gamma_{m}$ & 1 \\
$\sqrt{\sigma_{F}^{2}}$ & .1 \\
$\bar{u}_{m}$ & 10 \\
RGD & 0.5 \\
$R_{f}$ & 1.02
\end{tabular}

With these parameter choices, assuming regularity condition 4 is satisfied, and that the probability of default can have a Gaussian distribution, the quadratic equation implies $X_{m}$ is 1.0472. Given this choice of $X_{m}$ the unconditional probability of default, $\frac{X_{m}-\theta_{m}}{\bar{u}_{m}}$, is .04972. To check the approximate internal consistency of these values, I generated 10 million montecarlo draws from the true return distribution and estimated the default probability to be 
the fraction of return draws below 1.0472. A plus or minus two standard deviation confidence interval for the default probability is $[.0495, .0498]$, which contains the approximate probability of default.

To investigate the probability that condition 4 will be violated, note that the probability of a violation is

$$
\begin{aligned}
\operatorname{Prob}(\text { Violation }) & =1-\operatorname{Prob}\left(X_{m}-\theta_{m}>\gamma_{m} F+\epsilon_{m}>X_{m}-\theta_{m}-\bar{u}_{m}\right) \\
& =1-\left[\Phi\left(\frac{X_{m}-\theta_{m}}{\sqrt{\gamma_{m}^{\prime} \Sigma_{F}^{2} \gamma_{m}+\sigma^{2}\left(\epsilon_{m}\right)}}\right)-\Phi\left(\frac{X_{m}-\theta_{m}-\bar{u}_{m}}{\sqrt{\gamma_{m}^{\prime} \Sigma_{F}^{2} \gamma_{m}+\sigma^{2}\left(\epsilon_{m}\right)}}\right)\right] \\
& =1-(\Phi(4.9721)-\Phi(-95.028) \\
& =3.31 \times 10^{-7}
\end{aligned}
$$

The requirement that the fraction of defaults predicted by the model conditional on the factors is between 0 and 1, i.e. that the normality assumption is reasonable reduces to the condition in 4 .

The results here illustrate that using a normal distribution as an approximation for default probabilities and the return on a portfolio of loans from different sectors of the economy can be reasonable method for approximating default behavior, and creating returns on sector portfolios that are normally distributed.

There is one drawback of this approach. For simplicity, I used a uniform distribution for the variable $u_{m, s}$ over a support on $[0,10]$. If one uses a uniform random variable for the idiosyncratic return component, then its support has to be very large to generate plausible default probabilities. For example the upper bound 10 corresponds to a gross return of 1000 percent, with a gross average return of around 500 percent. This is not a problem unless one is hoping to also match data on the returns that entrepreneurs actually earn.

To match the entrepreneurs returns, then it is better to model $u_{s, m}$ as a random variable that has constant density for low values and then has a different distribution (such as terminating at a mass point) for higher values. For example, if $\operatorname{Prob}\left(u_{s, m}<k\right)=k / 10$ for $0 \leq k<1.5$, and $\operatorname{Prob}\left(u_{s, m}=1.5\right)=0.85$, then the upper bound on gross returns is much smaller, and will better fit the data, and by the law of large numbers the return for a well diversified portfolio will still turn out to be approximately Gaussian. 


\section{BIBLIOGRAPHY}

Allen, F., and D. Gale, 2000, "Financial Contagion," Journal of Political Economy 108, $1-33$.

Allen, L., and A. Saunders, 1986, "The Large-Small Bank Dichotomy in the Federal Funds Market," Journal of Banking and Finance 10, 219-230.

Allen, L.A., Peristani, S., and A. Saunders, 1989 "Bank Size, Collateral, and Net Purchase Behavior in the Federal Funds Market: Empirical Evidence," The Journal of Business, 62 , no. 4, 501-515.

Ashcraft, A., J. McAndrews, and D. Skeie, 2009, "Precautionary Reserves and the Interbank Market," Federal Bank of New York Staff Report no 370, May.

Bartolini, L., S. Hilton, and J. McAndrews, 2008, "Settlement Delays in the Money Market," Federal Reserve Bank of New York Staff Report no 319.

Bech, M.L., and E. Atalay, 2008, "The Topology of the Federal Funds Market," Federal Reserve Bank of New York Staff Report no. 354.

Board of Governors of the Federal Reserve System, 2009, "The Supervisory Capital Assessment Program: Design and Implementation", White Paper, Washington DC: Board of Governors, April 24.

Board of Governors of the Federal Reserve System, 2009, "The Supervisory Capital Assessment Program: Overview of Results", Report Accompanying Press Release, May 7, 2009.

Bossaerts, P., Ghirardato, P., Guarnaschelli, S., and W.R. Zame, 2010, "Ambiguity in Asset Markets: Theory and Experiment," Review of Financial Studies, 23, no. 4, 1325-1359.

Caballero, R.J., and A. Simsek, 2010, "Fire Sales in a Model of Complexity," MIT Working Paper 09-17.

Caballero, R.J., and A. Krishnamurthy, 2008, "Collective Risk Management in a Flight to Quality Episode," Journal of Finance, 63, no. 5, 2195-2236.

Cocco, J.F., Gomes, F.J., and N.C. Martins, 2009, "Lending Relationships in the Interbank Market," Journal of Financial Intermediation 18, 24-48.

Dang, T.V., Gorton, G., and B. Holmstrom, 2009, "Opacity and the Optimality of Debt for Liquidity Provision," Manuscipt, Yale University.

Duffie, D., and A. B. Ashcraft, 2007, "Systemic Illiquidity in the Federal Funds Market," American Economic Review, 97, no. 2., p. 221-225.

Duffie, D., and D. Lando, 2001, "Term Structure of Credit Spreads with Incomplete Accounting Information," Econometrica 69, 633-664.

Easley, D., and M. O'Hara, 2009, "Ambiguity and Nonparticipation: The Role of Regulation," Review of Financial Studies 22, no. 5, 1817-43.

Easley, D., and M. O'Hara, 2010, "Microstructure and Ambiguity," Journal of Finance, Forthcoming. 
Ellsberg, D., 1961, "Risk, Ambiguity, and the Savage Axioms," Quarterly Journal of Economics, 75, no. 4, 643-669.

Epstein, L. G., and M. Schneider, 2003, "Recursive Multiple-Priors," Journal of Economic Theory 113, 1-31.

Chen, Z., and L. G. Epstein, 2002 "Ambiguity, Risk, and Asset Returns in Continuous Time," Econometrica 70, no. 4, 1403-1443.

Furfine, C.H., 1999, "The Microstructure of the Federal Funds Market," Financial Markets, Institutions $\&$ Instruments, 24-44.

Furfine, C.H., 2001, "Banks as Monitors of Other Banks: Evidence from the Overnight Federal Funds Market," Journal of Business 74, 33-57.

Gilboa, I., and D. Schmeidler, 1989, "Maxmim Expected Utility with Non-Unique Prior," Journal of Mathematical Economics 18, 141-153.

Gorton, G., 2008, "The Panic of 2007," Maintaining Stability in a Changing Financial System, Federal Reserve Bank of Kansas City Jackson Hole Symposium, 131 - 262.

Guidolin, M., and F. Rinaldi, 2010, "Ambiguity in Asset Pricing and Portfolio Choice: A Review of the Literature," Working Paper 2010-028A, Federal Reserve Bank of St. Louis, September.

Hansen, L.P., and T.J. Sargent, 2008, Robustness, Princeton University Press, Princeton, N.J.

Heider, F., Hoerova, M., and C. Holthausen, 2009, "Liquidity Hoarding and Interbank Market Spreads: The Role of Counterparty Risk," Working Paper, The European Central Bank.

Ho, T. S. Y., and A. Saunders, 1985, "A Micro Model of the Federal Funds Market," The Journal of Finance, 40, no. 3, 977-988.

Klibanoff, P., Marinacci, M., and S. Mukerji, 2005, "A Smooth Model of Decision Making Under Ambiguity," Econometrica 73 no. 6, 1849-1892.

Park, S., 1991, "Bank Failure Contagion in Historical Perspective," Journal of Monetary Economics, 28, 271-286.

Pritsker, M., 2010, "Informational Easing: Improving Credit Conditions Through the Release of Information," Federal Reserve Bank of New York Econommic Policy Review, 77-87.

Schmeidler, D., 1989, "Subjective Probability and Expected Utility without Additivity," Econometrica, 57, 571-87.

Taylor, J.B., and J.C. Williams, 2009, "A Black Swan in the Money Market," American Economic Journal: Macroeconomics 1, no 1, 58-83.

Vasicek, O., 2002, "The Distribution of Loan Portfolio Value," Risk, December, p. 160-62.

Yu, F., 2005, "Acccounting transparency and the term structure of credit spreads," Journal of Financial Economics 75, 53-84. 
Table 1: Balance Sheet of Bank A

$\begin{array}{cc}\text { Assets } & \text { Liabilities } \\ \text { Loans 100 } & \text { Deposits } 80 \\ & \text { Equity } 20\end{array}$

Off balance sheet: Sold "bullet" protection on bank D that pays 25 if bank D defaults. 
Notes: For the bank optimization problem in section 2, the Figure illustrates the banks investment opportunity set in terms of the mean and standard deviation of the portfolios it can choose. The bank chooses its portfolio subject to a credit value at risk constraint (points on and above and to the left of the purple line satisfy the constraint). Its optimal portolio is $\bar{\omega}$, but because of internal constraints, it is assumed the bank instead chooses some mean-variance efficient portfolio between $\underline{\omega}$ and $\bar{\omega}$. 
Figure 2: Uncertainty Premium as a Function of Leverage and Loan Volatility

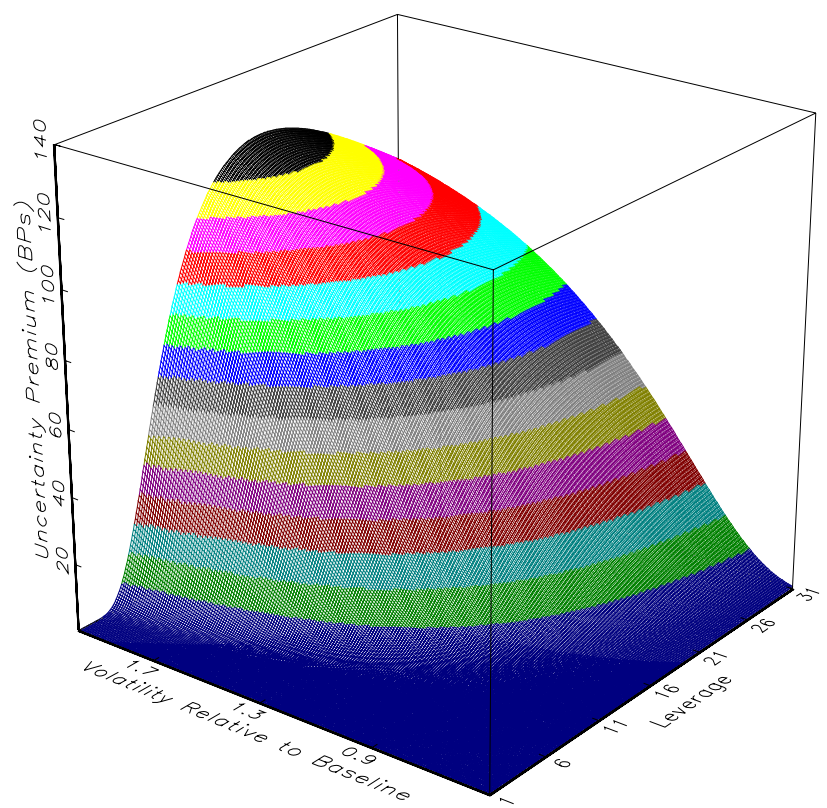

(a) Surface Plot

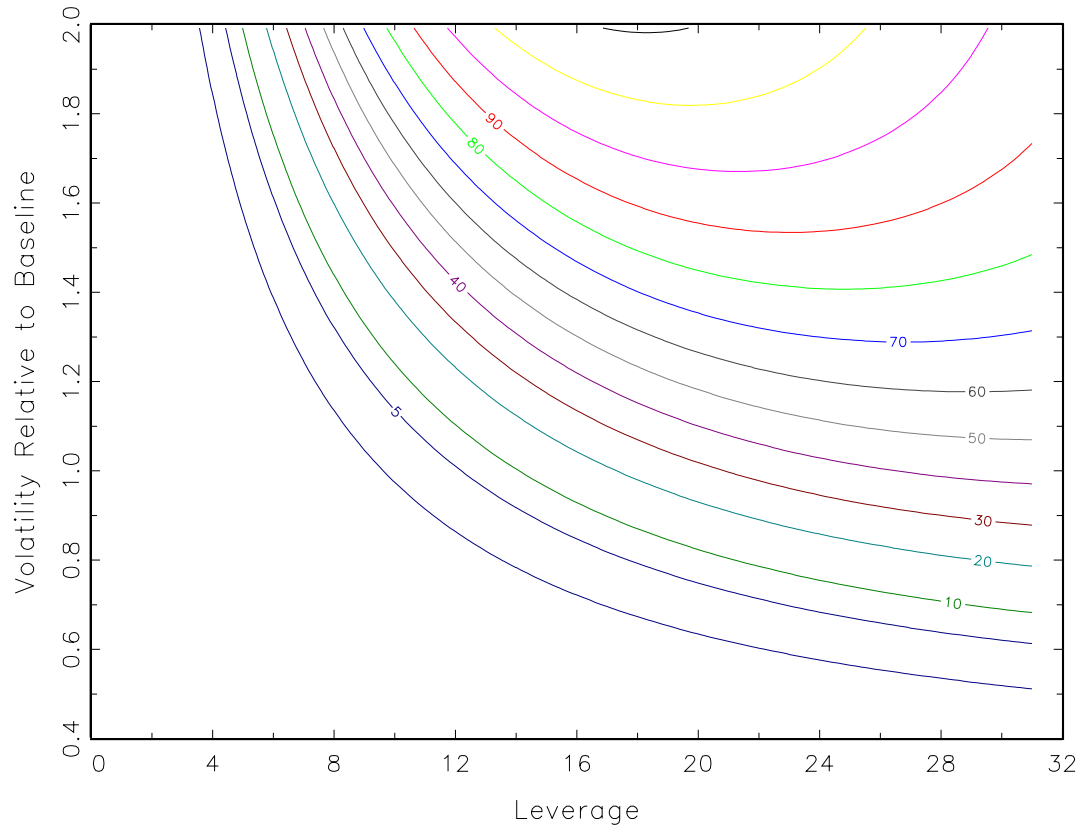

(b) Contour Plot

Notes: This Figure is reproduced from the author, forthcoming (2009). For a stylized bank that holds two risky assets in its loan portolio, the figure presents surface and contour plots of the uncertainty premium (in basis points) that the bank pays for its short-term unsecured interbank borrowing as a function of its leverage and as a function of the volatility (standard deviation) of it's assets relative to its baseline value. 
Figure 3: Economic Surplus from Government's Sequential Inspection and Announcement of Bank's Risk Exposures

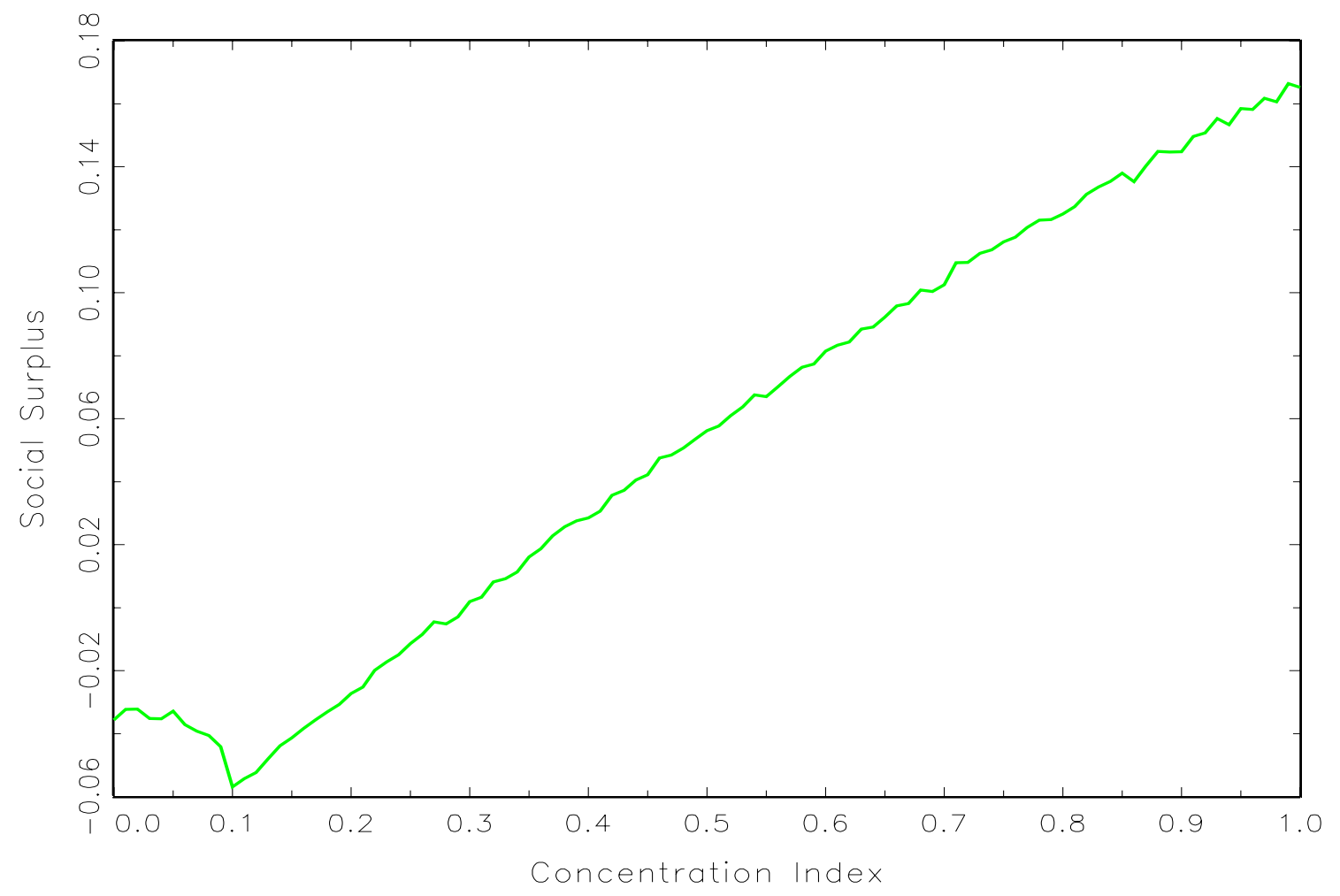

Notes: For a stylized example in which the interbank market breaks down due to uncertainty over banks risk exposures to a distressed class of assets, the figure presents a graph of the social surplus that is generated when the government follows a policy that involves sequentially inspecting and announcing the health and asset holdings of individual banks. The searches stop when liquidity is restored to the interbank market and when the surplus from interbank loans is judged to be high enough. Social surplus is a function of the true concentration of risk exposures within the banking sector to the distressed class of assets. Social surplus is measured in units of return per dollars of new entrepreneurial loans due to restoration of lending in the interbank market. Concentration is measured by an index that varies from 0 to 1 , where 0 represents minimal concentration of risky holdings, and 1 denotes maximal concentration of risky holdings. Additional details are provided in the text. 
Figure 4: Economic Surplus from Government's Sequential Inspection and Announcement Policy with Varying Government Inspection Costs and Random Search

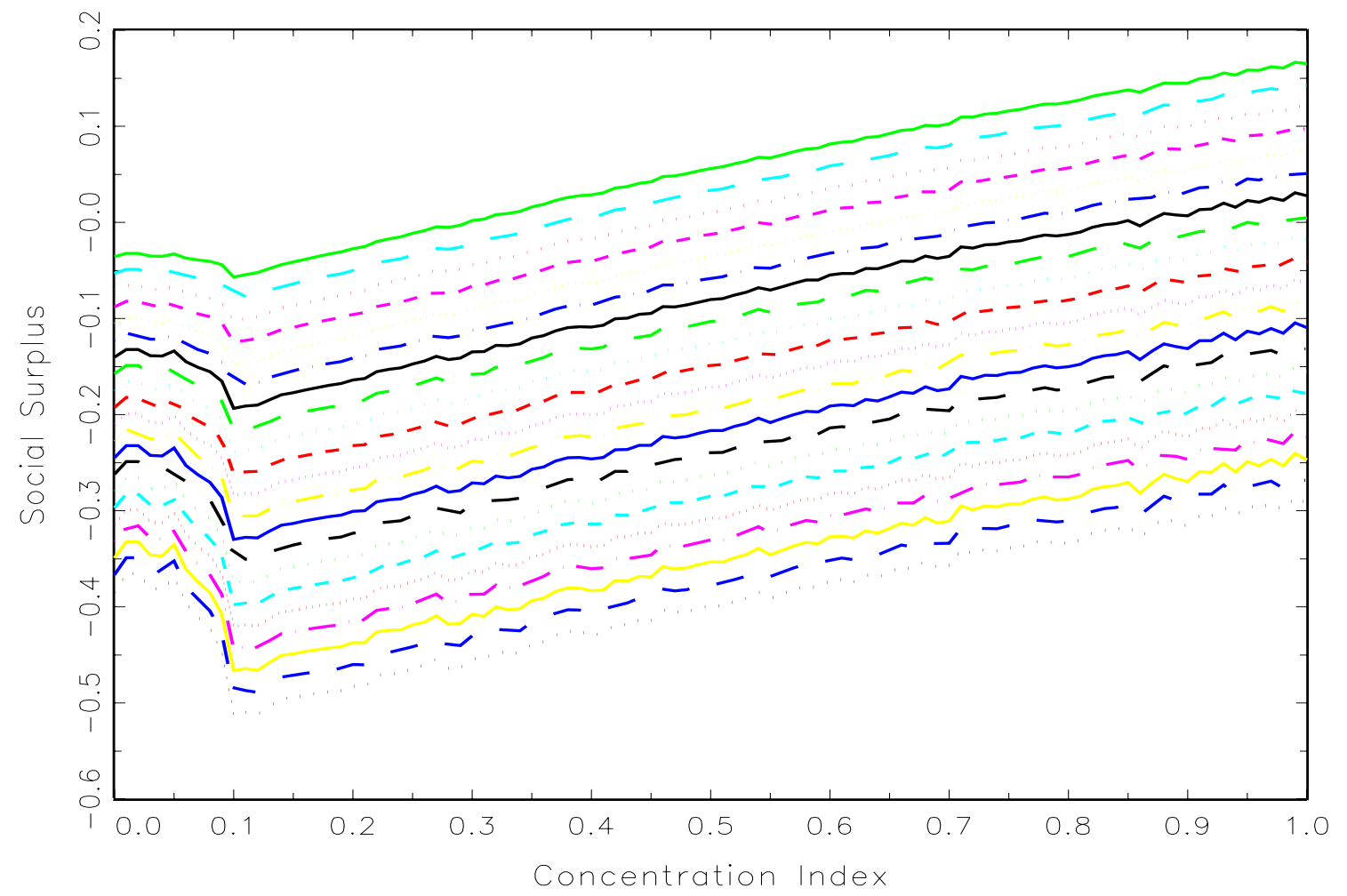

Notes: For the inspect and announce policy in Figure 3, this figure reports the surplus that is created if government's costs of evaluating each bank are equal to the banking sectors own costs multiplied by factors of 1.0, 1.1, 1.2, 1.3, etc... Results are presented for differing levels of concentration of banking sector exposure to the distressed asset class. For further details see Figure 3. 
Figure 5: Economic Surplus from Government's Sequential Inspection and Announcement Policy with Varying Government Inspection Costs and Search Based on Rank of Exposure

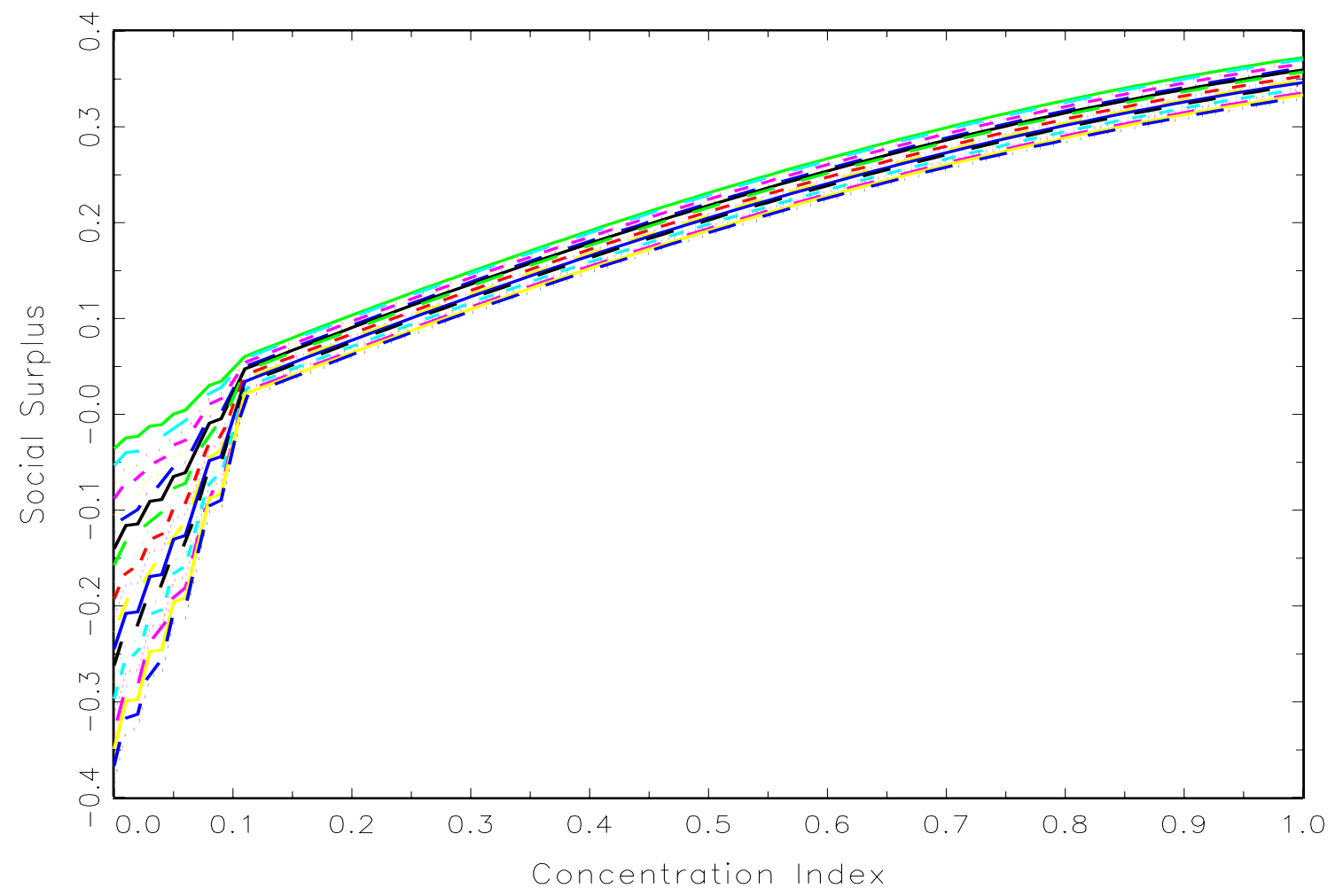

Notes: For the inspect and announce policy in Figure 3, and the cost structure in Figure 4, this figure reports the surplus that is created if government knows the relative magnitude of banks exposures to the distressed asset class and follows an inspect and announcement policy in which banks with higher risk exposures are inspected first, and in which inspections cease after the interbank market restarts. 
Figure 6: Interbank Spread as a Function of High Risk Assets Held by Banks: Good Economic Conditions

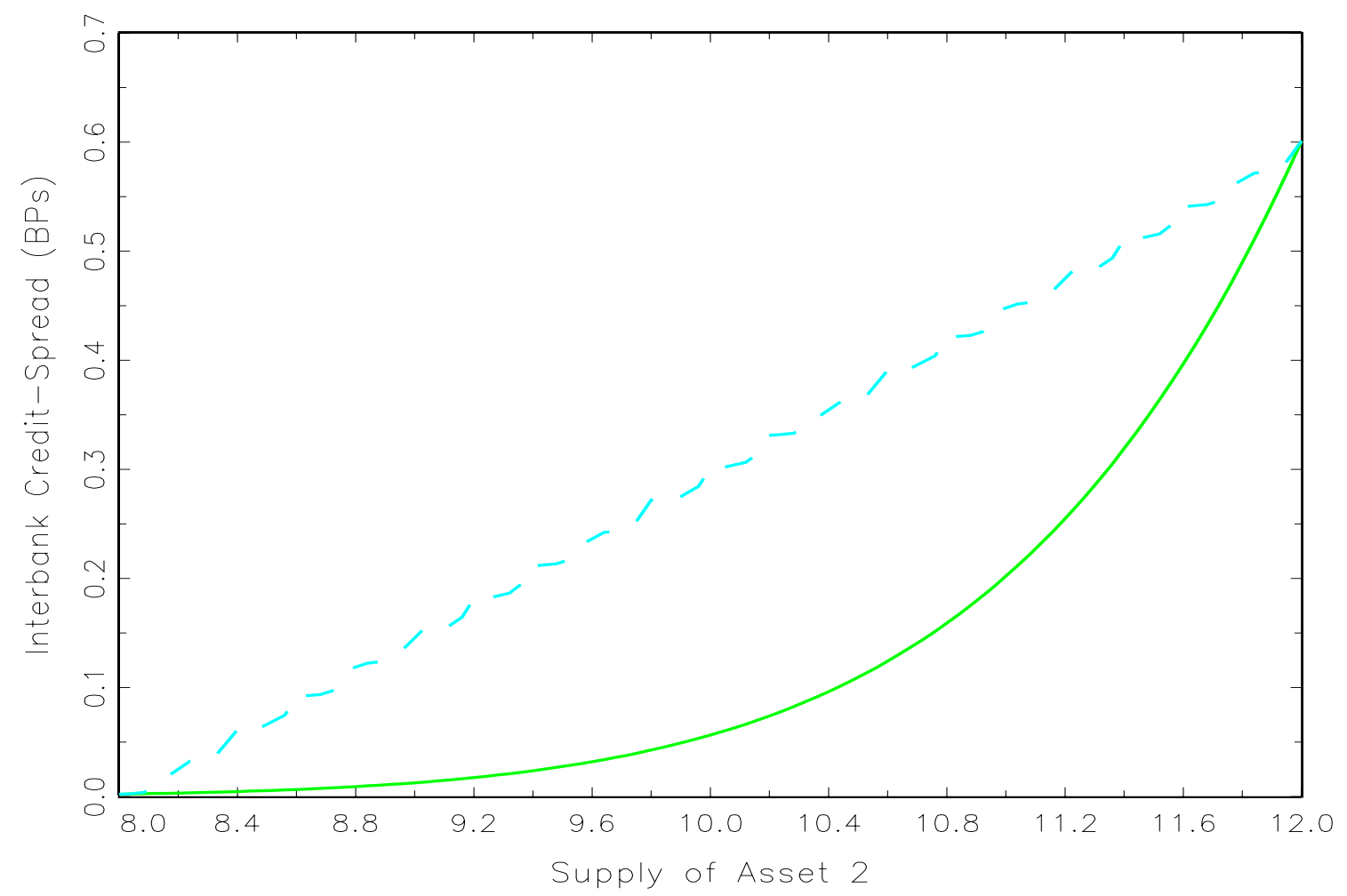

Notes: For the two risky asset example in section 3.3, for various levels of outstanding supply of risky asset 2, the figure illustrates the spread in a pooling equilibrium that banks have to pay when borrowing in the interbank market when assets are distributed among banks to maximize the spread (blue dashed line) and when assets are distributed among banks to minimize the spread (solid green line). The units on the y-axis are basis points. The figure shows regardless of supply, the spread is very low, i.e. at most it is just over $1 / 2$ basis point. 
Figure 7: Interbank Spread as a Function of High Risk Assets Held by Banks: Weak Economic Conditions

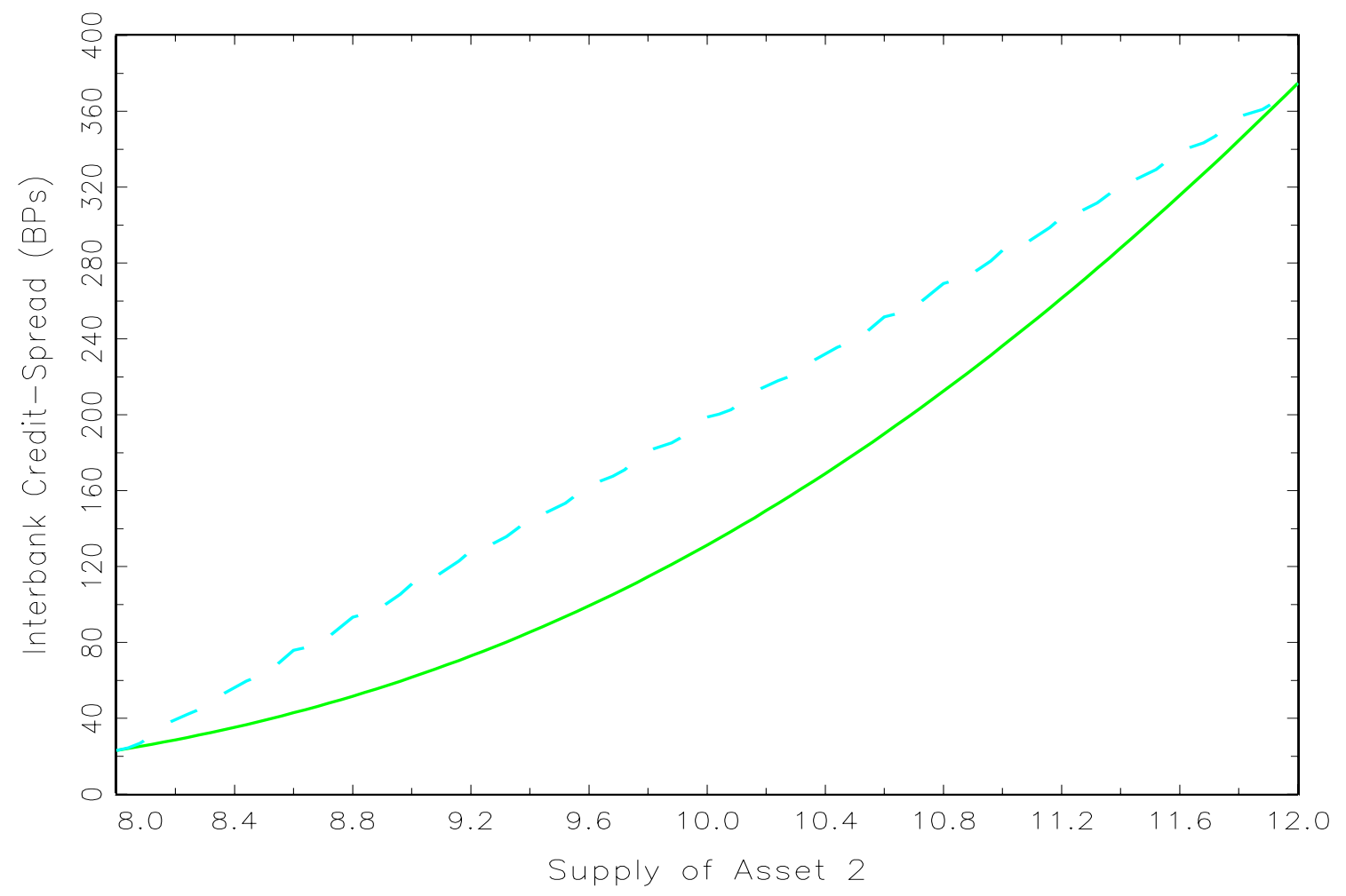

Notes: For the two risky asset example in section 3.3, for various levels of outstanding supply of risky asset 2, the figure illustrates the spread in a pooling equilibrium that banks have to pay when borrowing in the interbank market when assets are distributed among banks to maximize the spread (blue dashed line) and when assets are distributed among banks to minimize the spread (solid green line). The units on the y-axis are basis points. The figure shows in weak economic conditions the spread is very sensitive to the known outstanding amount of the risky asset held by banks. 